\title{
Fault-Tolerant Control in a Peak-Power Reduction System of a Traction Substation with Multi-String Battery Energy Storage System
}

\author{
Marcin Szott *, Marcin Jarnut, Jacek Kaniewski, Lukasz Pilimon (D) and Szymon Wermiński
}

check for updates

Citation: Szott, M.; Jarnut, M.; Kaniewski, J.; Pilimon, Ł.; Wermiński,

S. Fault-Tolerant Control in a

Peak-Power Reduction System of a

Traction Substation with Multi-String Battery Energy Storage System. Energies 2021, 14, 4565. https:// doi.org/10.3390/en14154565

Academic Editors:

Mohamed Benbouzid and

Mario Marchesoni

Received: 20 May 2021

Accepted: 24 July 2021

Published: 28 July 2021

Publisher's Note: MDPI stays neutral with regard to jurisdictional claims in published maps and institutional affiliations.

Copyright: (c) 2021 by the authors. Licensee MDPI, Basel, Switzerland. This article is an open access article distributed under the terms and conditions of the Creative Commons Attribution (CC BY) license (https:// creativecommons.org/licenses/by/ $4.0 /)$.
Institute of Automatic Control, Electronics and Electrical Engineering, University of Zielona Góra, St Prof. Z. Szafrana 2, 65-516 Zielona Góra, Poland; m.jarnut@iee.uz.zgora.pl (M.J.); j.kaniewski@iee.uz.zgora.pl (J.K.); l.pilimon@stud.uz.zgora.pl (Ł.P.); s.werminski@iee.uz.zgora.pl (S.W.)

* Correspondence: m.szott@iee.uz.zgora.pl

\begin{abstract}
This paper introduces the concept of fault-tolerant control (FTC) of a multi-string battery energy storage system (BESS) in the dynamic reduction system of a traction substation load (DROPT). The major task of such a system is to reduce the maximum demand for contracted peak power, averaged for $15 \mathrm{~min}$. The proposed concept, based on a multi-task control algorithm, takes into account: a three-threshold power limitation of the traction substation, two-level reduction of available power of a BESS and a multi-string structure of a BESS. It ensures the continuity of the maximum peak power demand at the contracted level even in the case of damage or disconnection of at least one chain of cells of the battery energy storage (BES) or at least one converter of the power conversion system (PCS). The proposed control strategy has been tested in a model of the system for dynamic reduction of traction substation load with a rated power of 5.5 MW. Two different BESS implementations have been proposed and several possible cases of failure of operations have been investigated. The simulation results have shown that the implementation of a multi-string BESS and an appropriate control algorithm (FTC) may allow for maintenance of the major assumption of DROPT, which is demanded power reduction (from 3.1 MW to $0.75 \mathrm{MW}$ ), even with a reduction of the BESS available power by at least $25 \%$ and more in the even in fault cases.
\end{abstract}

Keywords: fault-tolerant control; traction substation; battery energy storage system; peak-power reduction; demanded 15 min peak power; averaged 15 min power; three-threshold power limitation

\section{Introduction}

\subsection{Energy Storage Systems in Traction Application}

The basic cost incurred by the traction substation operator is usually the fee for the consumed energy [1], but also the fee for $15 \mathrm{~min}$ average power demand [2] as the fixed operating expenditure cost (OPEX) is considered [3]. Sometimes, for instance in Korea, the energy and power demand fee is charged additionally with the time-of-use tariff (TOU) [4], while the local distribution network operator (for example in Thailand) may also charge the traction substation operator with a service fee and a power factor fee [5].

There are various ways to limit the maximum instantaneous power and the demanded $15 \mathrm{~min}$ averaged power of traction substation. One of them may be the optimization of rolling stock movement by the introduction of an appropriate control algorithm based on the simplified Newton-Raphson method employs a set of current-balance equations at each electrical node [6]. Another effective way to reduce peak power demand, even by $40 \%$, could be the speed in motion and start-stop moments control of a given vehicle, based on two approaches: "Service Headway Braking" (SHB) and "Extending Stopping Distance Interval" (ESDI) [7], as well and the development of operational strategies and design strategies to reduce the energy consumption of overhead lines [8]. A good method of improving the energy efficiency (by $8 \%$ ) is the effective use of regenerative energy by 
dwell time optimization in urban rail transit using genetic algorithm [9], based on the traffic schedule of traction vehicles. It is also expected that the implementation of an on-board (OBESS) and a way-side (WESS) [10] or a track-side (TESS) [11] energy storage system could have a large impact on instantaneous as well as on demanded power reduction.

In the case of the OBESS structure, electric double-layer capacitors (EDLC) [11] are increasingly used. According to [5] the implementation of an OBESS with the peak demand reduction strategy may support reduction of the peak power by $63.49 \%$ and energy saving by $15.56 \%$ in a DC traction substation. A good and proven solution is also the implementation of flywheel energy storage (FES) [12]. On the other hand the use of some battery technologies, for example, nickel metal hydride (NiMH) technology, may be associated with a potential risk of cell explosion [11]. Although the implementation of a WESS [13] or TESS based on supercapacitor (SC) technology also has a positive effect on the peak power reduction [13], and the off-board location allows for a freer use of a wider group of energy storage (ES) technologies, especially lithium-ion (Li-ion) [14]. A very important aspect is also the optimal determination of the WESS location [15], which in turn may lead to a wider application, such as:

- $\quad$ voltage stabilization;

- energy saving;

- load levelling;

- peak power reduction [16].

The implementation of the energy storage system (ESS) in the traction substation as a part of a dynamic reduction system of the traction substation load (DROPT) [17] allows for the reduction of instantaneous power as well as for reduction of the demanded power, which directly reduces the fixed operating costs. Such a system can also limit voltage fluctuation and voltage drops on both the AC and DC sides [17]. Apart from partial peak power limitation, energy storage systems can also be used to accumulate regenerative energy and, in extreme cases, also to reserve power supply [18].

There are many papers considering energy storage systems, including their control and sizing in railway applications. For example the author of the article [19] proposes the control and operation of a single-phase 13-stage power conversion system (PCS) which, together with the energy storage (ES), is used to reduce the peak power of a high-speed railway substation (HSRS). In [20] two concepts of ESS implementation and their impact on the $15 \mathrm{~min}$ power demand limitation and reduction in energy consumption limitation have been considered. The authors have researched the SC energy storage and the more effective hybrid energy storage system (HESS) consisting of SC and the LFP (lithium iron phosphate battery- $-\mathrm{LiFePO}_{4}$ ), in which the $\mathrm{SC}$ is used for the utilization of regenerative energy, while the LFP battery is used to compensate the 15 min power demand of the TS in order to reduce power demand charge Both variants were also researched taking into account the payback time of the ESS investment. The Simple Payback Time (SPBT) of ESS implementation decreased from 15.9 to 10.8 years, using SC with LFP. In order to minimize the peak power of the traction substation and to better use the capacity of a BESS in urban rail transport, the article [21] proposes a strategy based on dynamic control of energy transfer that is based on state of charge $(\mathrm{SoC})$ regulation. The paper [22] presents a control strategy based on the SoC tracking in order to better use the ES capacity to reduce the peak power. For the dimensioning, location, optimal operation of the ESS and the appropriate energy management strategy, the authors of the article [23] introduce an optimization method that combines a genetic algorithm and a simulation platform of the urban rail power system. In [17], presented the BESS sizing method of a DROPT system determined by using a one-threshold power limitation. The proposed BESS dimensioning method and its implementation in the TS structure allows to significantly reduce the contracted power demand of a TS from $3 \mathrm{MW}$ to $0.8 \mathrm{MW}$. Further, the article [24] proposes a method with a two-threshold limitation allowing for more optimal BESS parameters of the DROPT system determination and shorting the SPBT of BESS by reducing the required BESS power 
from 5.26 MW to 2.26 MW and maintaining similar properties as DROPT system presented in [17].

The literature review mostly presents the aspects such as: methods of limiting peak power, methods of reduction the maximum demand for contracted peak power and energy consumption in the railway traction substation or in the traction vehicle equipped with an on-board, implementations of wayside or stationary energy storage system. The reviewed literature is focused methods of optimal dimensioning, selection of location of these systems and optimal selection of their storage technology. There are very important aspects discussed widely, but focusing only on the steady or dynamic state control in normal operating conditions, without focusing on emergency or failure state of BESS. It causes that their implementation in the TS structure may not fulfill their basic task. Due to the fact that there is still a lack for energy storage solution implemented in the dynamic reduction system of traction substation load which has been investigated in the case of fault or emergency cases, the fault tolerant control (FTC) method for BESS implemented in a TS has been proposed in this paper.

\subsection{Contribution of the Paper}

This paper presents the concept of the fault-tolerant control of a dynamic reduction system in a traction substation load (DROPT-FTC). The proposed control strategy uses a three-threshold power limitation method and enables the realization of the major task of DROPT, which is the limitation of the power demand even in the case of damage to the PCS segment or the BES chain. The proposed concept is based on the knowledge previously obtained in BESS dimensioning and control, using the one-threshold power limitation method presented in [17] and two-threshold power limitation method presented in [24]. In order to present and to test this concept, the real measurement data (load power flow, TS supply side power flow, charge and discharge power profile of BESS) obtained in a selected substation in which previously the DROPT system was implemented have been used. Whereas the optimally selected BESS, that is, power and energy have been determined previously for implementing DROPT system in a selected TS, using the one-threshold power limitation method [17] and the $15 \mathrm{~min}$ averaging method presented in [25].

The main contributions of this paper are:

- Presentation of the new control strategy concept of the DROPT-FTC system that tolerates damage of PCS or BES segments;

- Description of the decision algorithm and control method;

- Analysis of the DROPT-FTC system in several cases of single components failure;

- Determination of the range of the power limitation of the DROPT-FTC system in the event of failure of the BESS components which still allows for the maintenance of the assumed limitation of the demanded power.

\subsection{Structure of the Paper}

After the introduction, in the Section 2, the facility is analysed and the BESS operational parameters of the fully active DROPT-FTC system are presented. Section 3 presents the graph and describes the proposed control algorithm of a multi-string BESS, which allows for operational continuity in a fault event. Section 4 introduces two proposals of the structure of the BESS of the DROPT-FTC. In Section 5 the analysis of the two proposed structures of DROPT-FTC for several operational scenarios with BESS component failure (PCS or BES) have been commented on. Section 6 presents an analysis of the DROPT-FTC system maintenance reliability in the event of failure compared to a system with full power and energy availability. The article ends with Section 7, containing a short review and main conclusions, and Section 8 shows plans for future research. 


\section{Traction Substation with DROPT-FTC System}

\subsection{Basic Description of Proposed System}

The structure of a traction substation (TS) system with the proposed DROPT-FTC system has been shown in Figure 1. The DROPT-FTC system is connected to the direct voltage (DC) network at the point of common coupling (PCC), and consists of three basic modules:

- $\quad$ several parallel-connected DC/DC converters of the PCS system (multi-converter PCS);

- $\quad$ several parallel-connected BES link chains (multi-chain BES);

- $\quad$ BESS-SCADA master controller.

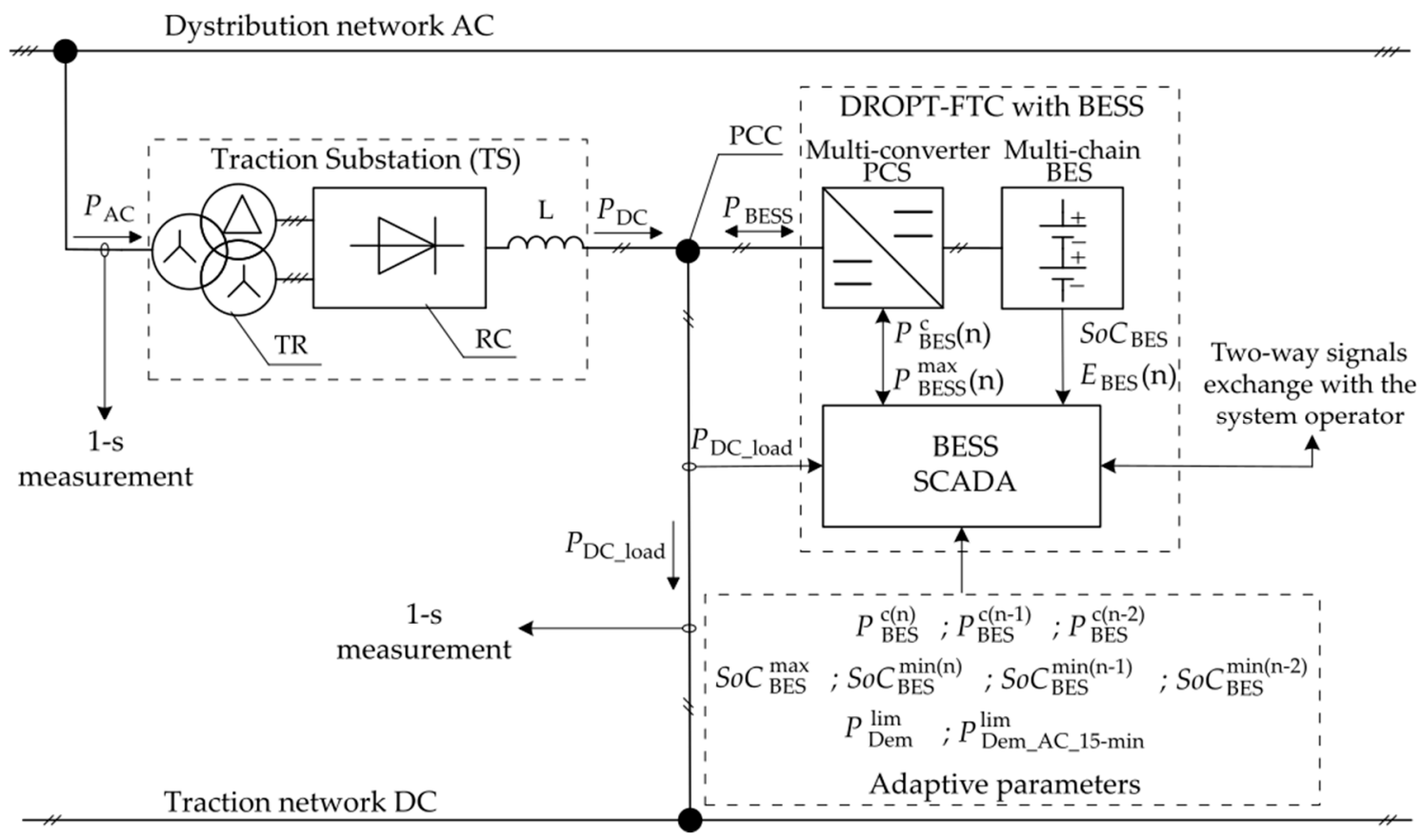

Figure 1. Simplified diagram of traction substation with DROPT-FTC system.

The master BESS-SCADA controller is responsible for: (i) controlling the PCS-CC controller of the PCS system; (ii) processing of the information obtained from the battery management system (BMS); (iii) voltage and current measurements processing; (iv) realization of the main control algorithm and (v) information exchange with the external systems.

The two major tasks of the DROPT-FTC system are:

- reduction and maintenance of the demanded (contracted) 15 min peak power $P \lim _{\text {Dem_AC_avg }(15-\min )}$ at the assumed and adjusted level;

- reduction of instantaneous power $P_{\mathrm{AC} \_a v g(1-\mathrm{s})}^{\max }$ (full effectiveness possible only in failure-free state of DROPT-FTC).

The basic parameters of the TS and the DROPT-FTC system have been introduced in Table 1. The presented data refers to the real object (one of the traction substations in Western Poland) where the dynamic load reduction system of a traction substation (DROPT [17]) was successfully implemented at the beginning of 2021 and where the FTC control is planned to be implemented to improve system reliability in the cases of PCS or BES partial failure.

The Table 1 shows the value of $P_{\mathrm{BESS}}$ and $E_{\mathrm{BES}}$ parameters of the BESS when PCS and BES are working in the normal state. Due to the required cycle life of the BES, based on the Li-ion technology [26], it needs to be kept at a high state of charge for the high discharge power rates $\left(C_{\text {rate }} \geq 3 C\right.$ ) [27] specific for dynamic systems like the considered DROPT system, with the operation of the system in the range between $S o C_{\mathrm{BES}}^{\min (n)}=40 \%$ 
and $S o C_{\mathrm{BES}}^{\max }=90 \%$ being assumed [28]. It strictly results from cycle life characteristic of NMC (Nickle Manganese Cobalt) cells implemented in DROPT system. Although this assumption reduces the available energy $E_{\mathrm{BES}}^{\mathrm{DROPT}-\mathrm{FTC}(\max )}$ by half in comparison to the rated energy $E_{\mathrm{BES}}^{\mathrm{DROPT}-\mathrm{FTC}(\mathrm{R})}$ of BES of the DROPT-FTC system, it guarantees a longer lifetime of the battery cells [29] in an application with a high number of very dynamic power flow cycles [27]. The operation and lifetime of the DROPT has been planned for least 15 years [24].

During the development process of DROPT system the investment costs as well as period of proper operation were taken into account. The optimal BES parameters were obtained for the above minimum and maximum SoC threshold.

Table 1. Basic parameters of TS and DROPT-FTC.

\begin{tabular}{ccccccccc}
\hline & \multicolumn{4}{c}{ TS } & \multicolumn{4}{c}{ DROPT-FTC } \\
\hline$P_{\text {TS }}^{\mathbf{R}}$ & $\boldsymbol{P}_{\text {Dem_AC_avg(15-min) }}$ & $\boldsymbol{P}_{\text {Dem_AC_avg(15-min) }}^{\text {lim }}$ & $P_{\text {BESS }}^{\text {DROPT-FTC }}$ & $E_{\text {BES }}^{\text {DROPT-FTC(R) }}$ & $E_{\text {BES }}^{\text {DROPT-FTC(max) }}$ & $S o C_{\text {BES }}^{\max }$ & $S o C_{\text {BES }}^{\min (\mathbf{n})}$ \\
\hline $\mathbf{M W})$ & $\mathbf{( M W )}$ & $\mathbf{( M W )}$ & $\mathbf{( M W )}$ & $\mathbf{( M W h )}$ & $\mathbf{( M W h )}$ & $\mathbf{( \% )}$ & $\mathbf{( \% )}$ \\
\hline 6.30 & 3.10 & 0.75 & 5.50 & 1.80 & 0.90 & 90 & 40 \\
\hline
\end{tabular}

\subsection{Load Reduction with DROPT-FTC in Normal State}

The typical (measured) weekly power profiles of instantaneous $P_{\mathrm{AC}}$ avg $(1-\mathrm{s})$ ( $1 \mathrm{~s}$ averaged) and the $15 \mathrm{~min}$ average $P_{\mathrm{AC} \_ \text {avg }(15-\min )}$ powers on the $\mathrm{AC}$ side of above mentioned traction substation are shown in Figure 2. The real measurements have been recorded using power quality recorders and the analysis of the measurement data $\left(P_{\mathrm{AC} \_ \text {avg }(1-\mathrm{s})}\right)$ was performed in the RStudio using a 15 min average method [25] in accordance with the EN standards $[30,31]$.

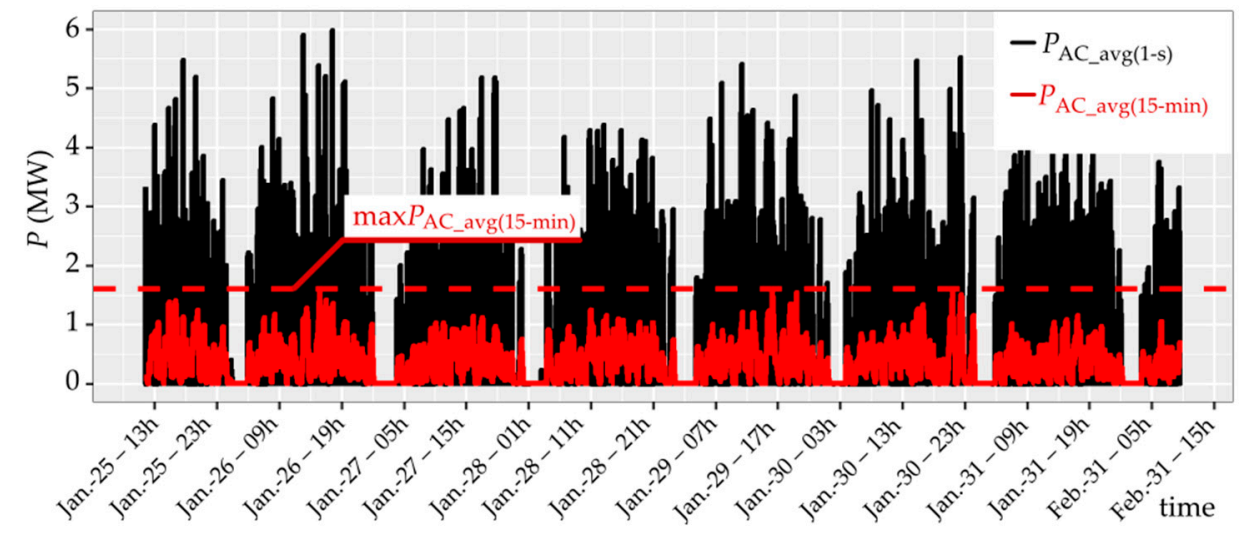

Figure 2. Typical weekly power profiles on AC side of traction substation.

The daily power profiles of $P_{\mathrm{AC} \_a v g(1-\mathrm{s})}$ and $P_{\mathrm{AC} \_ \text {avg }(15-\min )}$ in normal state have been shown in Figures 3 and 4 (with DROPT-FTC system inactive and with DROPT-FTC system activated respectively). 


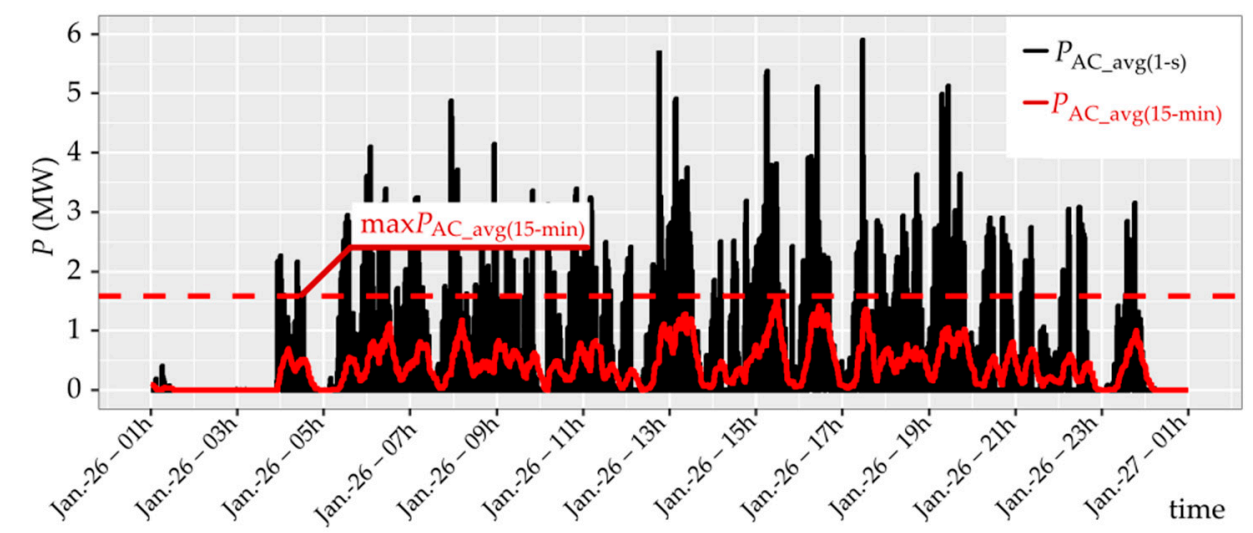

Figure 3. Daily power profile on AC side of the TS with DROPT-FTC inactive.

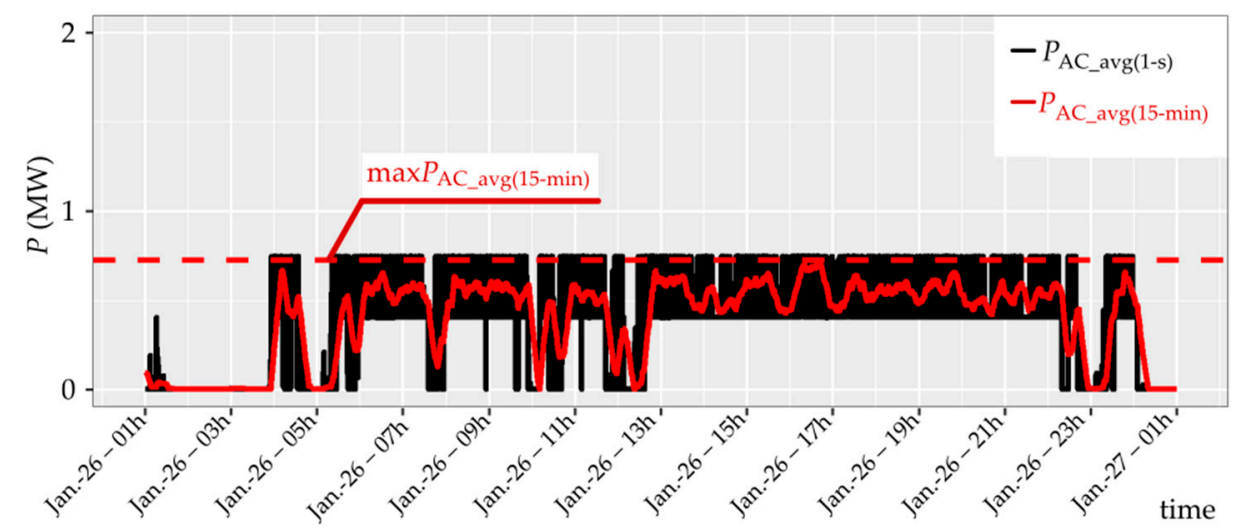

Figure 4. Daily power profiles on AC side of TS with DROPT-FTC activated.

As can be seen in Figure 4 in a normal state, without any failure in PCS and in BESS, the instantaneous power on the AC side of TS has been reduced below the adjusted level (0.75 MW) using power balancing in PCC. The deficit in load power has been covered by power $P_{\mathrm{BESS}}^{\mathrm{d}}$ delivered from the energy storage side (Figure 5).

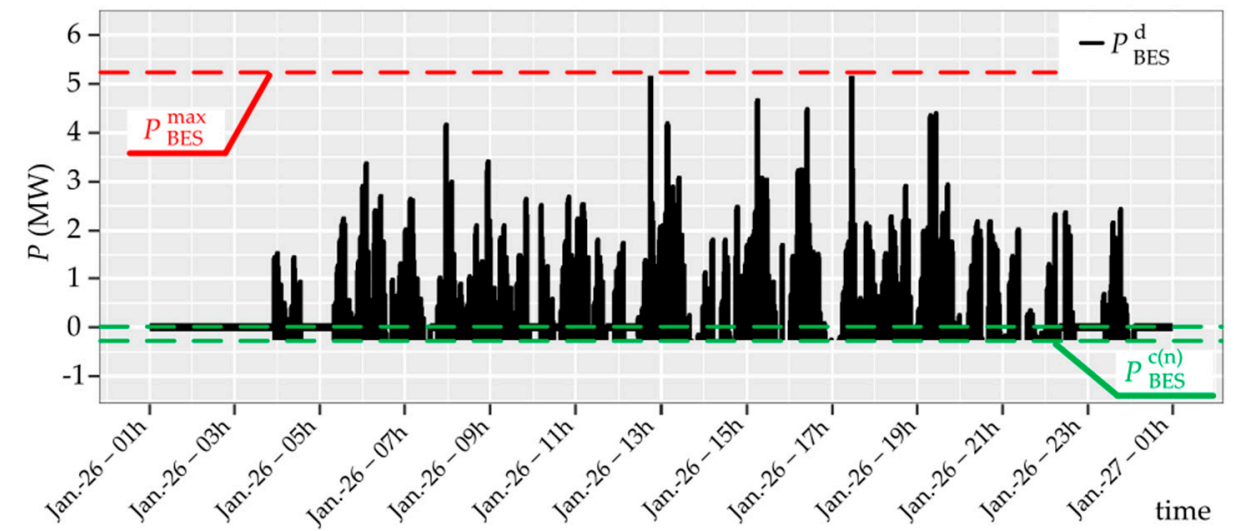

Figure 5. Daily power profile of BESS in normal state of DROPT-FTC.

During the traffic hours power balancing in PCC leads to discharging of energy storage (BESS) down to $40 \%$ of SoC. BESS is charged back to $90 \%$ at night hours when the train traffic drops down. The daily state of charge $S o C_{B E S}$ profile of BESS corresponding to daily power profile (Figure 5) has been introduced in Figure 6. 


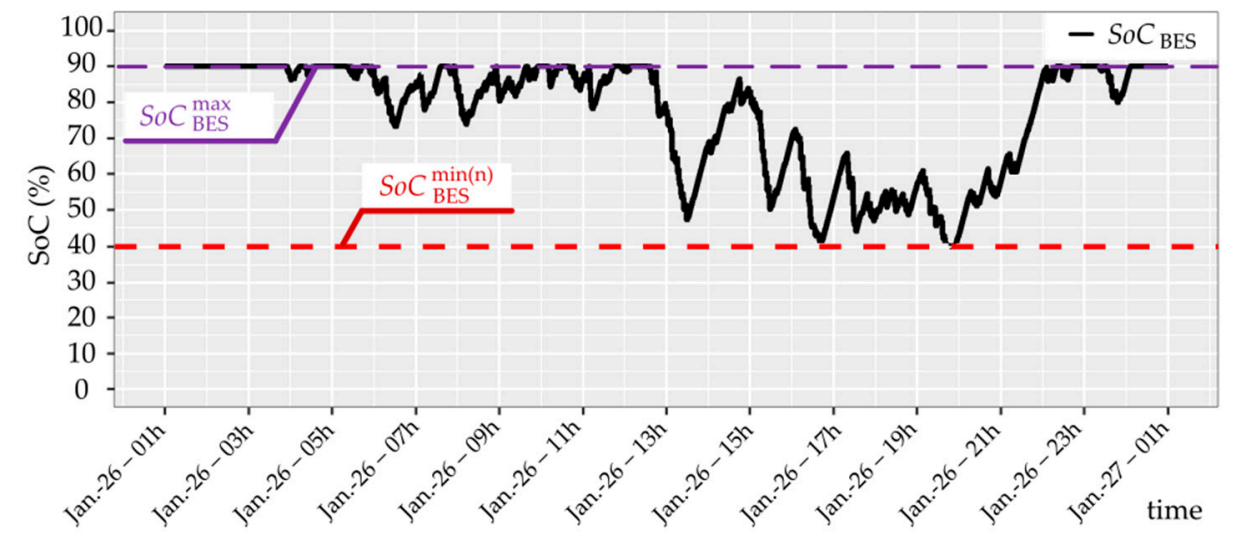

Figure 6. Daily state of charge $S o C_{\mathrm{BES}}$ profile of BESS in normal state of DROPT-FTC.

\section{Fault-Tolerant Control of Multi-String Battery Energy Storage System}

\subsection{Adaptation of Power Limits in DROPT-FTC}

Referring to the structure and principal of operation of the DROPT system presented in [17] and based on the one-threshold or two-threshold limitation of instantaneous power [24], the DROPT-FTC system based on a three-threshold limitation has been proposed. This system in the (n-1) status, when one PCS or one chain of BES cells is damaged or disconnected, enables the keeping of the major assumption, which is to maintain the demanded power $P_{\text {Dem_AC_avg }}(15-\min )$ of the traction substation below the adjusted limit. Moreover, the proposed control strategy and the BESS structure may allow the maintenance of the major assumption even in the status (n-2).

The proposed method with a three-threshold reduction strategy has been introduced in Figure 7.

a)

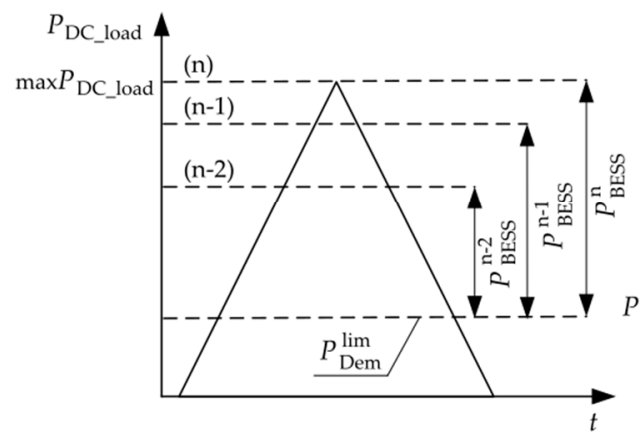

b)

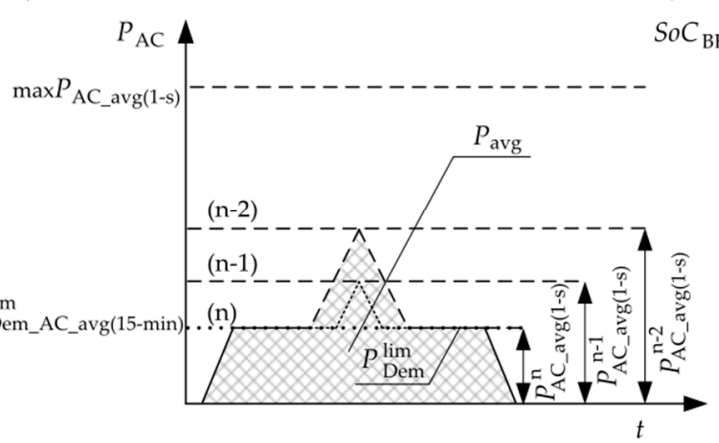

c)

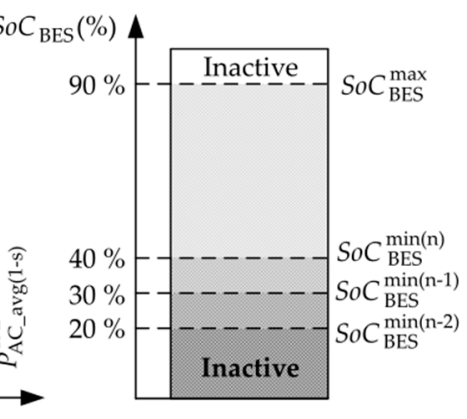

Figure 7. Adaptation of power limits in DROPT-FTC system: (a) three-threshold power limits; (b) average power in considered cases; (c) state of charge variation in the case of $S o C(\mathrm{n}) ;(\mathrm{n}) \forall \mathrm{n}, \mathrm{n}-1, \mathrm{n}-2$.

In the considered DROPT-FTC system the below listed parameters have the following meaning:

- $\quad P_{\mathrm{BESS}}^{\mathrm{n}}$ - power limit of BESS in a one-threshold reduction strategy in the normal state of the BESS, when all of PCS and BES strings are available;

- $\quad P_{\mathrm{BESS}}^{\mathrm{n}-1}$ - power limit of BESS in a two-threshold reduction strategy in a state of limited availability of the BESS, when at least one PCS or BES string is damaged or disconnected;

- $\quad P_{\mathrm{BESS}}^{\mathrm{n}-2}$ - power limit of BESS in three-threshold reduction strategy in state of limited availability of the BESS, when at least two PCSs or BES strings are damaged or disconnected; 
- $\quad$ Pem - $\lim$-demanded power limit, parameter controlled by DROPT-FTC system, maximum value of $15 \mathrm{~min}$ averaged power $P_{\mathrm{Dem}}^{\lim }$

- $\quad P_{\mathrm{AC} \_a v g(1-\mathrm{s})}^{\mathrm{n}} ; P_{\mathrm{AC} \_ \text {avg }(1-\mathrm{s})}^{\mathrm{n}-1} ; P_{\mathrm{AC} \_ \text {avg }(1-\mathrm{s})}^{\mathrm{n}-2}$-instantaneous powers on the $\mathrm{AC}$ side of traction substation: in normal state, $\mathrm{n}-1$ state and $\mathrm{n}-2$ state respectively.

The three-threshold power reduction strategy could be provided as follows:

- one-threshold reduction strategy, of so-called "bottom-up adaptation" [17,24], in which the maximum instantaneous power $\max P_{\mathrm{AC} \_a v g(1-\mathrm{s})}$ is reduced by balancing DC load power $P_{\mathrm{DC} \_ \text {load }}$ with the BESS available power $P_{\mathrm{BESS}}^{\mathrm{n}}$ to be below the level: $P_{\mathrm{AC} \_ \text {avg }(1-\mathrm{s})}^{\mathrm{n}} \leq P_{\text {Dem_AC_avg }(15-\mathrm{min})}^{\lim }=P_{\mathrm{Dem}}^{\lim } ;$

- two-threshold reduction strategy, of so-called "top-down adaptation" [24] in which the maximum instantaneous power $\max P_{\mathrm{AC} \text { avg(1-s) }}$ is reduced by balancing DC load power $P_{\mathrm{DC} \_l o a d}$ with the available power $P_{\mathrm{BESS}}^{\mathrm{n}-1}$ to be below the level: $P_{\mathrm{AC} \_ \text {avg }(1-\mathrm{s})}^{\mathrm{n}-1}>$ $P_{\text {Dem_AC_avg }(15-\min )}=P_{\text {Dem }}^{\lim }$;

- three-threshold reduction strategy, of so-called "top-down adaptation" in which the maximum instantaneous power $\max P_{\mathrm{AC} \_a v g(1-s)}$ is reduced by balancing DC load power $P_{\mathrm{DC} \_ \text {load }}$ with the available power $P_{\mathrm{BESS}}^{\mathrm{n}-2}$ to be below the level: $P_{\mathrm{AC} \_ \text {avg(1-s) }}^{\mathrm{n}-2} \gg$ $P_{\text {Dem_AC_avg }(15-\min )}=P_{\text {Dem }}^{\lim }$.

Summarizing the above considerations and dependencies:

$>$ the first-threshold is directly proportional to $P_{\mathrm{Dem}}^{\lim }$;

$>$ the second-threshold depends on the available power of BESS when one PSC or BES fails;

$>$ the third-threshold is depends on the available power of BESS when two PCS or BES fails.

In the one-threshold reduction strategy, the balancing with available power of BESS reduces the maximum instantaneous power $\max P_{\mathrm{AC} \_a v g(1-s)}$ on the $\mathrm{AC}$ side of TS equal to $\max P_{\mathrm{DC} \_ \text {load }}$ of the TS below the level $P_{\mathrm{Dem} \_\mathrm{AC}}^{\lim \text { avg }(15-\min )}$, while in the two-threshold and three-threshold reduction strategies, the reduced available power of BESS still allows the maintenance of $P_{\text {Dem_AC_avg }(15-\min )}$ at a very similar level, but does not allow the reduction of the instantaneous power below this level.

\subsection{Control Algorithm of the DROPT-FTC}

The simplified graph of the multi-function control algorithm is shown in Figure 8. This algorithm allows the control of the DROPT-FTC system in the state of its partial failure, with the single PCS or BES segments being damaged or disconnected. The basis of its functionality rests on the knowledge about the state or status of each PCS or BES segment. This knowledge is translated into available power or energy by the algorithm performing specific functions based on a few major dependencies:

$$
\left\{\begin{array}{l}
P_{\mathrm{BESS}}^{\mathrm{DROPT}}=f\left(P_{\mathrm{PCS}}(\mathrm{n})\right) ; \forall \mathrm{n}, \mathrm{n}-1, \mathrm{n}-2 \\
P_{\mathrm{BESS}}^{\mathrm{DROPTC}}=f\left(P_{\mathrm{BES}}(\mathrm{n})\right) ; \forall \mathrm{n}, \mathrm{n}-1, \mathrm{n}-2 \\
E_{\mathrm{BES}}^{\mathrm{DROPT}-\mathrm{FTC}(\max )}=f\left(E_{\mathrm{BES}}(\mathrm{n})\right) ; \forall \mathrm{n}, \mathrm{n}-1, \mathrm{n}-2 \\
E_{\mathrm{BES}}^{\mathrm{DROPT}-\mathrm{FTC}(\max )}=f\left(P_{\mathrm{BES}}(\mathrm{n})\right) ; \forall \mathrm{n}, \mathrm{n}-1, \mathrm{n}-2 \\
E_{\mathrm{BES}}^{\text {DROPT-FTC }(\max )}=f\left(\operatorname{SoC}_{\mathrm{BES}}(\mathrm{n})\right) ; \forall \mathrm{n}, \mathrm{n}-1, \mathrm{n}-2
\end{array} .\right.
$$




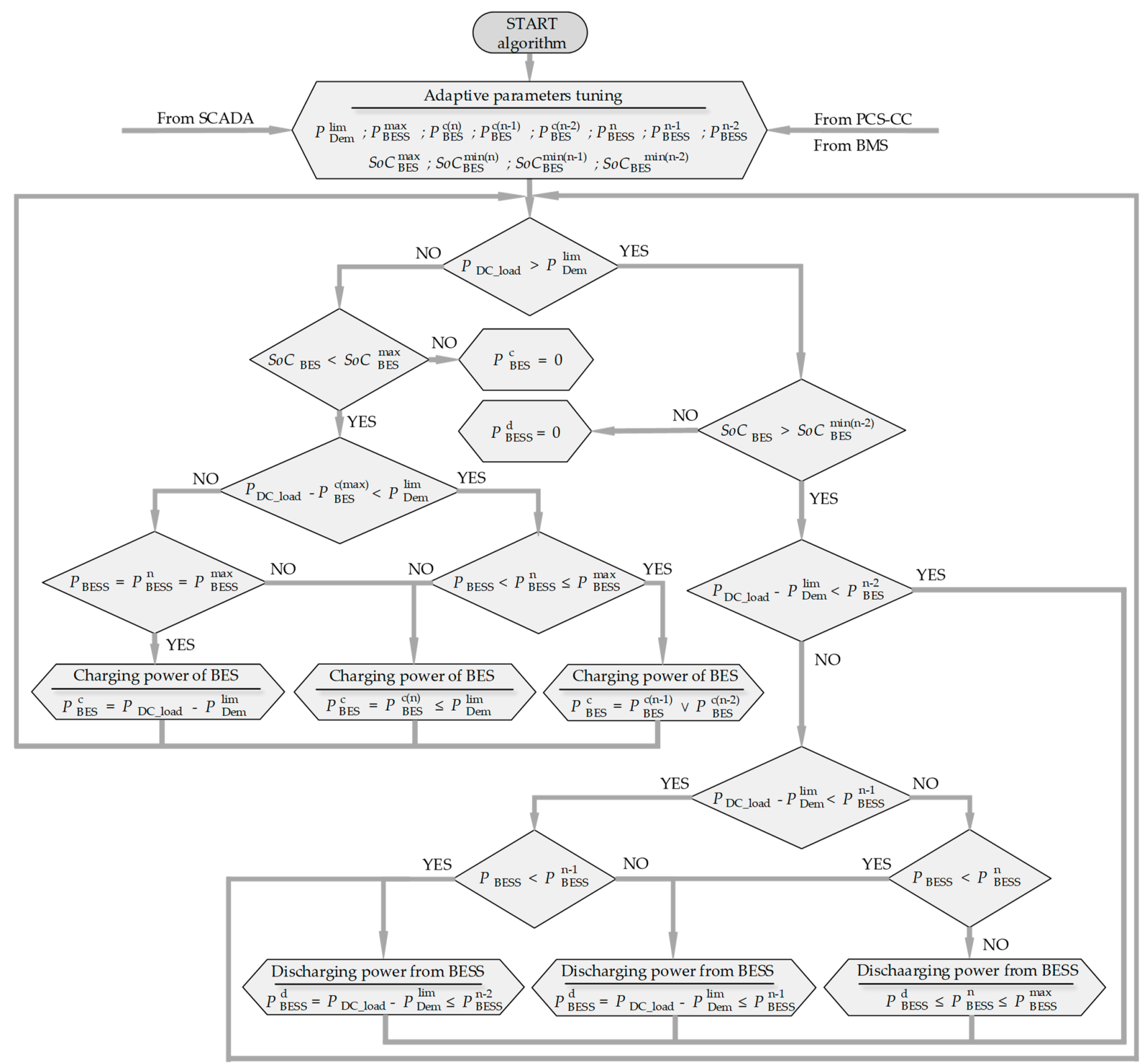

Figure 8. Simplified flowchart of multi-function, fault-tolerant control algorithm of DROPT-FTC system.

In the different states with full or limited availability of DROPT-FTC elements the algorithm also performs the following functions:

$$
\left\{\begin{array}{l}
P_{\mathrm{BES}}^{\mathrm{c}}=f\left(\operatorname{So}_{\mathrm{BES}}(\mathrm{n})\right) ; \forall \mathrm{n}, \mathrm{n}-1, \mathrm{n}-2 \\
P_{\mathrm{BES}}^{\mathrm{c}}=f\left(P_{\mathrm{BES}}(\mathrm{n})\right) ; \forall \mathrm{n}, \mathrm{n}-1, \mathrm{n}-2 \\
P_{\mathrm{BES}}^{\mathrm{c}}=f\left(P_{\mathrm{BESS}}(\mathrm{n})\right) ; \forall \mathrm{n}, \mathrm{n}-1, \mathrm{n}-2 \\
P_{\mathrm{BESS}}^{\mathrm{d}}=f\left(P_{\mathrm{BESS}}(\mathrm{n})\right) ; \forall \mathrm{n}, \mathrm{n}-1, \mathrm{n}-2 \\
P_{\mathrm{BESS}}^{\mathrm{d}}=f\left(\operatorname{SoC}_{\mathrm{BES}}^{\min }(\mathrm{n})\right) ; \forall \mathrm{n}-2
\end{array},\right.
$$

where: $P_{\mathrm{BES}}^{\mathrm{c}}$ is the charge power of BES; $P_{\mathrm{BESS}}^{\mathrm{d}}$ is the discharge power of BESS. 
In the proposed algorithm the loss of available energy of BES is compensated by gradual adjustment of minimum discharge limitation $S o C_{\mathrm{BES}}^{\min }$ of $\mathrm{BES}$ according to:

$$
\left\{\begin{array}{l}
S o C_{\mathrm{BES}}^{\min (\mathrm{n})}=40 \% S o C_{\mathrm{BES}}^{\max (\mathrm{R})} ; \forall \mathrm{n} \\
S o C_{\mathrm{BES}}^{\min (\mathrm{n}-1)}=30 \% S o C_{\mathrm{BES}(\mathrm{R})}^{\max (\mathrm{R})} ; \forall \mathrm{n}-1 . \\
S o C_{\mathrm{BES}}^{\min (\mathrm{n}-2)}=20 \% S o C_{\mathrm{BES}}^{\max (\mathrm{R})} ; \forall \mathrm{n}-2
\end{array} .\right.
$$

The $S o C$ parameter is not measurable in practical applications. In simulation research presented in this paper the well-known and simple method based on coulomb counting (CC) [32] has been used to estimate $\mathrm{SoC}$ instantaneous value. In each considered state of DROPT system the $S o C$ value has been calculated in relation to available capacity of BES. All simulations performed in RStudio use the real load data obtained in a real object with the parameters presented in Table 1.

The strategy of gradual limitation of the minimum level $S o C_{\mathrm{BES}}^{\min }$ from $40 \%$ down to $20 \%$ allows an increase in the available energy $E_{\mathrm{BES}}^{\max }$ in case of disconnection or damage of the BESS segments.

Referring to the above, the most important aspect of the DROPT-FTC system is the dynamic change of the depth of discharge $(D o D)(4)$ parameter, which is directly influenced on the maximum available energy $E_{\mathrm{BES}}^{\max }$ as a result of gradual change of $S o C_{\mathrm{BES}}^{\min }$ :

$$
D o D=S o C_{\mathrm{BES}}^{\max }-S o C_{\mathrm{BES}}^{\min }(\mathrm{n}) ; \forall \mathrm{n}, \mathrm{n}-1, \mathrm{n}-2 .
$$

The $S o C_{\mathrm{BES}}^{\min }$ thresholds of BES in a states $\mathrm{n}, \mathrm{n}-1, \mathrm{n}-2$ and $S o C_{\mathrm{BES}}^{\max }$ of the DROPT-FTC system were determined in the following ways. Firstly, we took into account knowledge about cyclic life [33] and the possibility of permanent damage to cells of BES in Li-ion technology [28]. The $S o C_{\mathrm{BES}}^{\min (\mathrm{n})}=40 \%$ threshold for the system operation in a failure-free state was established with the aim of obtaining the highest possible lifecycles [34] of BESS implemented in a DROPT system that works with large and frequently changing load, where BESS needs to be kept at a high state of discharge power rates $\left(C_{\text {rate }} \geq 3 C\right)$ [35]. The $S o C_{\mathrm{BES}}^{\max }=90 \%$ threshold was adopted in order to avoid excessive degradation of BES cells [28] and, as indicated in the paper [36], in order to obtain the total energy throughput for $D o D$ of $10 \%$. Such a model for determining the SoC thresholds was adapted for the real DROPT system implemented in TS in Western Poland, the basic data of which are presented in Section 2.1, and for which the preliminary research was carried out in paper [17]. The $S_{0} C_{\mathrm{BES}}^{\min (n-2)}=20 \%$ threshold for the system operation in a failure state was established to increase the available energy $E_{\mathrm{BES}}^{\mathrm{max}}$ in case of failure state of the BESS segments. This threshold is not recommended to be exceeded due to a reduction in the lifecycle of BES by increasing the degradation of cells and the possibility of its permanent damage [28]. It is especially in dynamic charge/discharge states [29], which can significantly reduce the period of proper operation of DROPT system [17] by reduction BES service life. Thus the control algorithm also provides checking of the lower SoC limit $S o C_{\mathrm{BES}}^{\min } \geq 20 \% S o C_{\mathrm{BES}}^{\max (\mathrm{R})}$ and similarly also the upper SoC limit $S o C_{\mathrm{BES}}^{\max } \leq 90 \% \mathrm{SoC}_{\mathrm{BES}}^{\max (\mathrm{R})}$.

$S o C_{\mathrm{BES}}^{\min (\mathrm{n})}, S o C_{\mathrm{BES}}^{\min (\mathrm{n}-1)}, S o C_{\mathrm{BES}}^{\min (\mathrm{n}-2)}$ and $S o C_{\mathrm{BES}}^{\max }$ limits are implemented in the simulation model, where $S o C_{\mathrm{BES}}^{\max }$ and $S o C_{\mathrm{BES}}^{\min (n)}$ remain constant values, while $S o C_{\mathrm{BES}}^{\min (\mathrm{n}-1)}=30 \%$ and $S o C_{\mathrm{BES}}^{\min (\mathrm{n}-2)}=20 \%$ are automatically adjusted in case of the available energy reduction due to damage or disconnection of one PCS or BES (status n-1) or two PCS or BES (status n-2).

Such functionality will not lead to a significant reduction in the volume of the cycling life, because damage or disconnection of a given BESS segment occurs rarely and additionally the service response time to the removal of a defect is a maximum of $24 \mathrm{~h}$ and results directly from the contract between the investor and integrator of the implemented DROPT system. 
The control strategy (Figure 8) provides a gradual adjustment of the charging power $P_{\mathrm{BES}}^{\mathrm{c}}(2)$ depending on the physical state of the BESS (of n; n-1; n-2 status), gradual decrease of minimal SoC level $S o C_{\mathrm{BES}}^{\min }$ and the available power $P_{\mathrm{BESS}}$ (in case of $\mathrm{n} ; \mathrm{n}-1 ; \mathrm{n}$-2 status). The available power of BESS and the charging power values are selected from the data table. The maximum value $P_{\mathrm{BES}}^{\mathrm{c}(\mathrm{n})}=0.420 \mathrm{MW}$ was determined as a result of optimization of the real DROPT system implemented in the TS in Western Poland operating in a fault-free state. The charging power $P_{\mathrm{BES}}^{\mathrm{c}(\mathrm{n}-1)}$ and $P_{\mathrm{BES}}^{\mathrm{c}(\mathrm{n}-2)}$ thresholds have been established as a result of many simulation research.

\section{Case Study of the DROPT-FTC System}

\subsection{Available Power and Energy of Battery Energy Storage System}

The power and available energy of the DROPT-FTC system is proportional to the power of the PCS and the energy of the BES, and depends on the quantity of active PCS segments and BES cell chain. The control strategy (Figure 8) provides a gradual adjustment of the charging power $P_{\mathrm{BES}}^{\mathrm{c}}(2)$ depending on the physical state of the BESS (of n; n-1;n-2 status), gradual decrease of the $S o C$ minimal level $S o C_{\mathrm{BES}}^{\min }$ and the available power $P_{\mathrm{BESS}}$ (in case of $n ; n-1 ; n-2$ status). Multi-string BESS allows the operation of DROPT-FTC in the event of a fault, but the available BESS power $P_{\mathrm{BESS}}^{\mathrm{DROPT}-\mathrm{FTC}}(5)$ is directly proportional to the sum of the power of the available active segments of PCS:

$$
P_{\mathrm{BESS}}^{\mathrm{DROPT}-\mathrm{FTC}}=P_{\mathrm{PCS}}(\mathrm{n}),
$$

where:

$$
P_{\mathrm{PCS}}(\mathrm{n})=P_{\mathrm{PCS}(1)}+P_{\mathrm{PCS}(2)}+P_{\mathrm{PCS}(3)}+\ldots+P_{\mathrm{PCS}(m)},
$$

and $(1) ;(2) ; \ldots(\mathrm{m})$ represent successive segments of PCS.

As it can be concluded from (6), the more $P_{\text {PCS }}$ components leads to the less impact on the power reduction of the DROPT-FTC system.

The available energy $E_{\mathrm{BES}}^{\mathrm{DROPT}-\mathrm{FTC}}(7)$ value is directly proportional to the sum of the energies of the available active strings of BES (8) connected to individual PCS segments:

$$
E_{\mathrm{BES}}^{\mathrm{DROPT}-\mathrm{FTC}}=E_{\mathrm{BES}}(\mathrm{n}),
$$

where:

$$
E_{\mathrm{BES}}(\mathrm{n})=E_{\mathrm{BES}(1)}+E_{\mathrm{BES}(1)}+E_{\mathrm{BES}(1)}+\ldots+E_{\mathrm{BES}(\mathrm{m})},
$$

and $(1) ;(2) ; \ldots$ (m) represent successive link chains of BES.

As it follows from the dependences (8), the more $E_{\mathrm{BES}}$ components, the less impact on the reduction of the available energy of the DROPT-FTC system has the lack of availability of single BES chain or PCS segment.

Taking into account the above, a multi-stringing of DROPT-FTC structure could reduce the impact on the power availability and available energy in the event of a single segment failure may slightly affect the contracted level of the demanded power $P_{\text {Dem_AC_avg }(15-\min )}^{\lim }$ of the traction substation.

\subsection{Multi-String Energy Storage System}

In order to verify the proposed control strategy presented in Section 3, two BESS structure were proposed (Figures 9 and 10). The simulation research were performed for both structure. The simulated structures do not directly reflect the actual real DROPT system implemented in the TS in Western Poland. They are intended to investigate if the FTC control strategy could have similar effect in different solutions. 


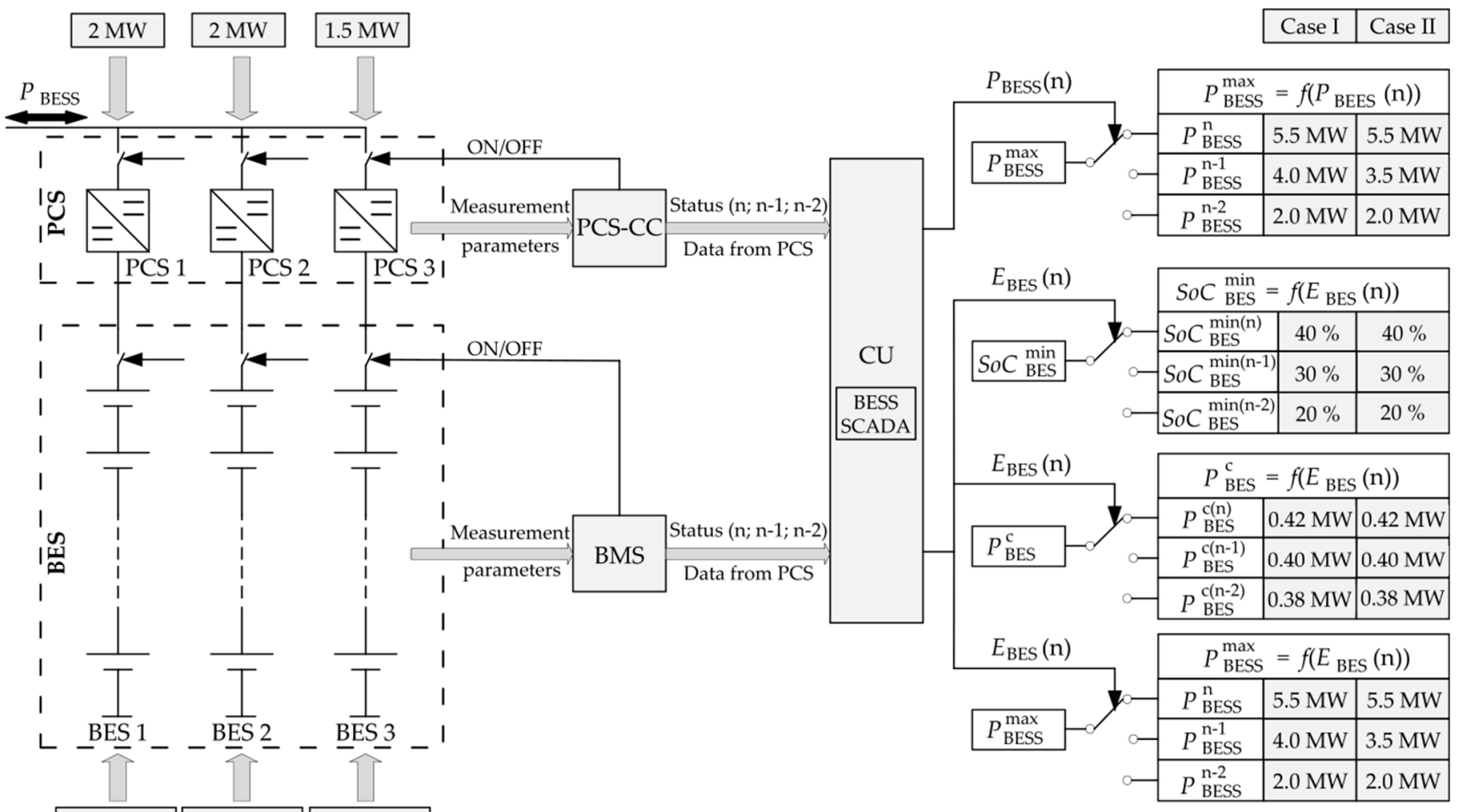

\section{$0.655 \mathrm{MWh} 0.655 \mathrm{MWh} 0.490 \mathrm{MWh}$}

Figure 9. Illustration of the generalized parameter adaptation algorithm in DROPT-FTC with a three-string asymmetrical BESS.
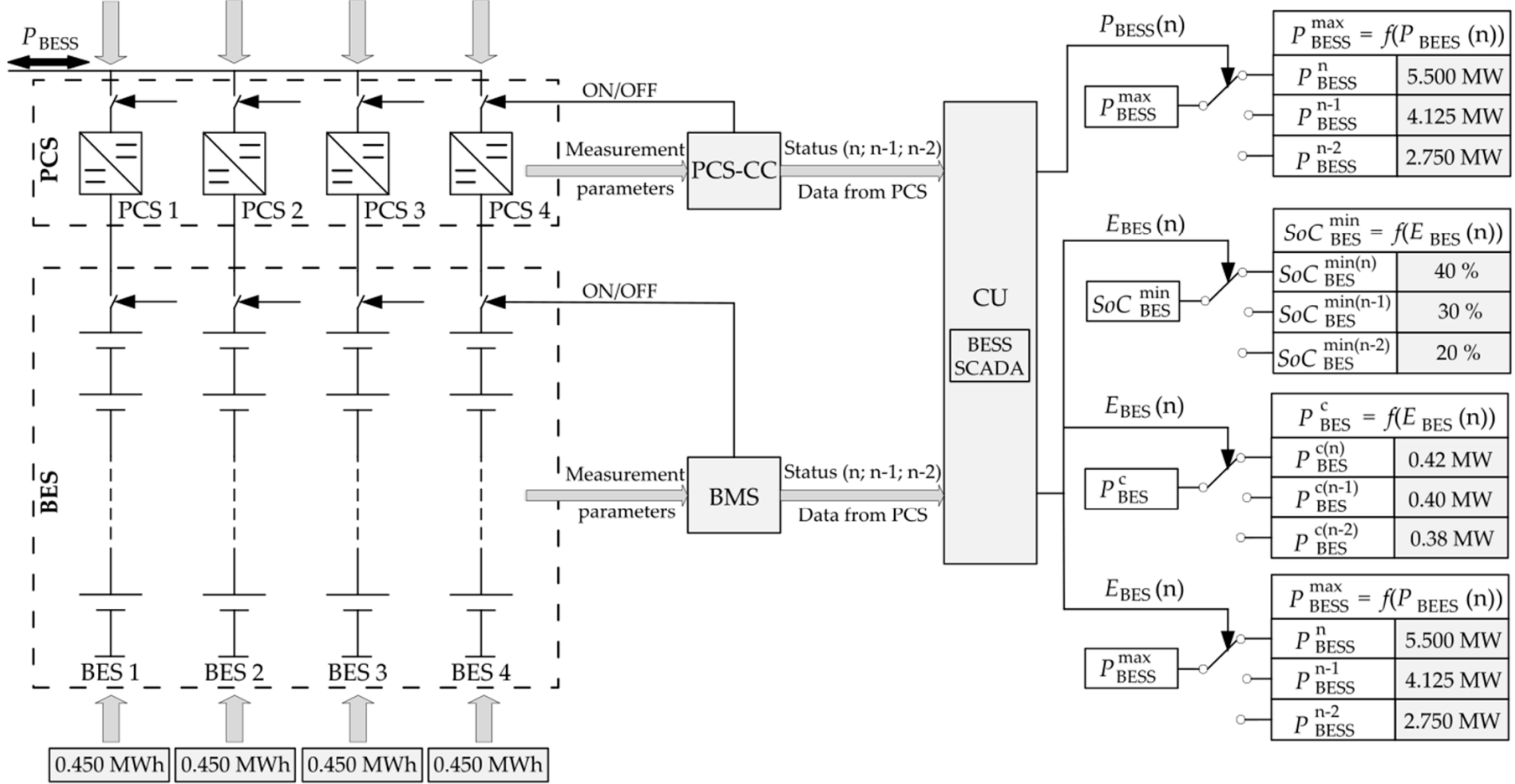

Figure 10. Illustration of the generalized parameter adaptation algorithm in DROPT-FTC with a four-string symmetrical BESS. 
Figure 9 shows an example of a three-string BESS structure with a rated power $P_{\mathrm{BESS}}^{\mathrm{DROPT}-\mathrm{FTC}}=5.5 \mathrm{MW}$. Available power and energy have been divided between three asymmetrical segments. In this case, we took into account PCS segments with a rated power of 2.0 MW and 1.5 MW, while the BES available energy was divided proportionally to the power of a given chain of cells in order to maintain the same value of the factor $C$-rate:

$$
C-\text { rate }=\frac{P_{\mathrm{BES}}}{E_{\mathrm{BES}}} \cong \frac{P_{\mathrm{PCS}}}{E_{\mathrm{BES}}}
$$

Figure 10 shows in turn an example of the four-string BESS structure with the same rated power $P_{\mathrm{BESS}}^{\mathrm{DROPT}-\mathrm{FTC}}=5.5 \mathrm{MW}$, but the available power and energy have been divided between four symmetrical segments. In this case PCS segments have a rated power 1.375 MW each. The available energy of BES was divided proportionally to the power of a given chain of cells in order to maintain the same value of the C-rate (9).

\section{Analysis of the DROPT-FTC with Proposed Fault-Tolerant Algorithm}

\subsection{Basic Parameters for Simulation Research}

Table 2 shows the basic parameters of the proposed three-string asymmetrical BESS (Figure 9), whereas in Table 3 shows the basic parameters of the proposed four-string symmetrical BESS (Figure 10).

Table 2. Parameters of the proposed three-string BESS.

\begin{tabular}{lcccccccc}
\hline Parameters & $\sum$ PCS & PCS (1) & PCS (2) & PCS (3) & $\sum$ BES & BES (1) & BES (2) & BES (3) \\
\hline$P_{\mathrm{PCS}}(\mathrm{MW})$ & 5.500 & 2.000 & 2.000 & 1.500 & - & - & - & - \\
\hline$E_{\mathrm{BES}}(\mathrm{MWh})$ & - & - & - & - & 1.800 & 0.655 & 0.655 & 0.490 \\
\hline
\end{tabular}

Table 3. Parameters of the proposed four-string BESS.

\begin{tabular}{lcccccccccc}
\hline Parameters & $\sum$ PCS & PCS (1) & PCS (2) & PCS (3) & PCS (4) & $\sum$ BES & BES (1) & BES (2) & BES (3) & BES (4) \\
\hline$P_{\mathrm{PCS}}(\mathrm{MW})$ & 5.500 & 1.375 & 1.375 & 1.375 & 1.375 & - & - & - & - & - \\
\hline$E_{\mathrm{BES}}(\mathrm{MWh})$ & - & - & - & - & - & 1.800 & 0.450 & 0.450 & 0.450 & 0.450 \\
\hline
\end{tabular}

The basic parameters of three- and four-string BESS used in the simulation research have been introduced in Table 4. Several possible scenarios have been considered (from CASE $\mathrm{I}_{\mathrm{A}}$ to CASE III $_{\mathrm{C}}$ ) for DROPT-FTC system structure shown in Figures 9 and 10 and when one or two segments (PCS or BES) were damaged or disconnected. In the analysis it has been assumed: (n) is the normal state of PCS and BES, (n-1) means failure or disconnection of single PCS or BES component and (n-2) stands for two-segment failure. It has also been assumed the efficiency of the BESS system at the level of $\eta \sim 96 \%$, therefore the available power has been limited to the level of $96 \%$ (10) in relation to the powers given in Tables 2 and 3 for each of the proposed scenarios.

$$
P_{\mathrm{BESS}}^{\max }(\mathrm{n})=96 \% P_{\mathrm{BESS}}^{\mathrm{DROPT}-\mathrm{FTC}}(\mathrm{n}) ; \forall \mathrm{n}, \mathrm{n}-1, \mathrm{n}-2 .
$$


Table 4. Basic parameters of three- and four-string BESS used in simulation research.

\begin{tabular}{|c|c|c|c|c|c|c|c|c|c|c|}
\hline \multirow{2}{*}{ Parameters } & \multicolumn{2}{|c|}{ Base } & \multicolumn{5}{|c|}{ Three-String BESS } & \multicolumn{3}{|c|}{ Four-String BESS } \\
\hline & Rated & $\begin{array}{c}\text { Normal } \\
\text { (n) }\end{array}$ & $\begin{array}{c}\text { CASE } \\
I_{A}(n-1)\end{array}$ & $\begin{array}{c}\text { CASE } \\
I_{B}(n-1)\end{array}$ & $\begin{array}{l}\text { CASE } \\
I_{C}(n-2)\end{array}$ & $\begin{array}{c}\text { CASE } \\
\mathrm{II}_{\mathrm{A}} \\
(\mathbf{n}-1)\end{array}$ & $\begin{array}{c}\text { CASE } \\
\mathrm{II}_{\mathrm{B}} \\
(\mathrm{n}-1)\end{array}$ & $\begin{array}{c}\text { CASE } \\
\text { III } \\
(n-1)\end{array}$ & $\begin{array}{c}\text { CASE } \\
\text { III } \\
(\mathbf{n}-1)\end{array}$ & $\begin{array}{c}\text { CASE } \\
\text { III }_{C} \\
(\mathrm{n}-2)\end{array}$ \\
\hline$P_{\mathrm{BESS}}^{\max }(\mathrm{MW})$ & 5.500 & 5.260 & 3.840 & 3.840 & 1.920 & 3.360 & 3.360 & 3.960 & 3.960 & 2.630 \\
\hline$E_{\mathrm{BES}}^{\max }(\mathrm{MWh})$ & 1.800 & 0.900 & 0.786 & 0.916 & 0.458 & 0.687 & 0.802 & 0.810 & 0.945 & 0.630 \\
\hline$S o C_{\mathrm{BES}}^{\max }(\%)$ & 100 & 90 & 90 & 90 & 90 & 90 & 90 & 90 & 90 & 90 \\
\hline$S o C_{\mathrm{BES}}^{\min (\mathrm{n})}(\%)$ & 0 & 40 & - & - & - & - & - & - & - & - \\
\hline$S o C_{\mathrm{BES}}^{\min (\mathrm{n}-1)}(\%)$ & - & - & 30 & - & - & 30 & - & 30 & - & - \\
\hline So $C_{\mathrm{BES}}^{\min (\mathrm{n}-2)}(\%)$ & - & - & - & 20 & 20 & - & 20 & - & 20 & 20 \\
\hline$P_{\mathrm{BES}}^{\mathrm{c}}(\mathrm{n})(\mathrm{MW})$ & - & 0.420 & 0.400 & 0.380 & 0.380 & 0.400 & 0.380 & 0.400 & 0.380 & 0.380 \\
\hline
\end{tabular}

For systems (n); (n-1); (n-2) the BESS efficiency of $\eta \sim 96 \%$ has been took into account.

\subsection{Result of Simulation Research}

The simulations of DROPT-FTC, in several cases defined in Table 4, has been performed to verify the effectiveness of the proposed FTC algorithm. The influence of partial failure of a single or two segments of BESS on instantaneous and demanded power on the AC side of TS as well as on the minimal SoC level of BES have been considered in each scenario.

Figure 11 shows the simulation results of a three-string BESS in CASE $\mathrm{I}_{\mathrm{A}}$ for $(\mathrm{n}-1)$ state, where: $P_{\mathrm{BESS}}^{\max }=3.840 \mathrm{MW}$, and $S o C_{\mathrm{BES}}^{\min (\mathrm{n}-1)}=30 \%, E_{\mathrm{BES}}^{\max }=0.786 \mathrm{MWh}, P_{\mathrm{BES}}^{\mathrm{c}(\mathrm{n}-1)}=0.400 \mathrm{MW}$, $P P_{\text {Dem }}=0.750 \mathrm{MW}$.
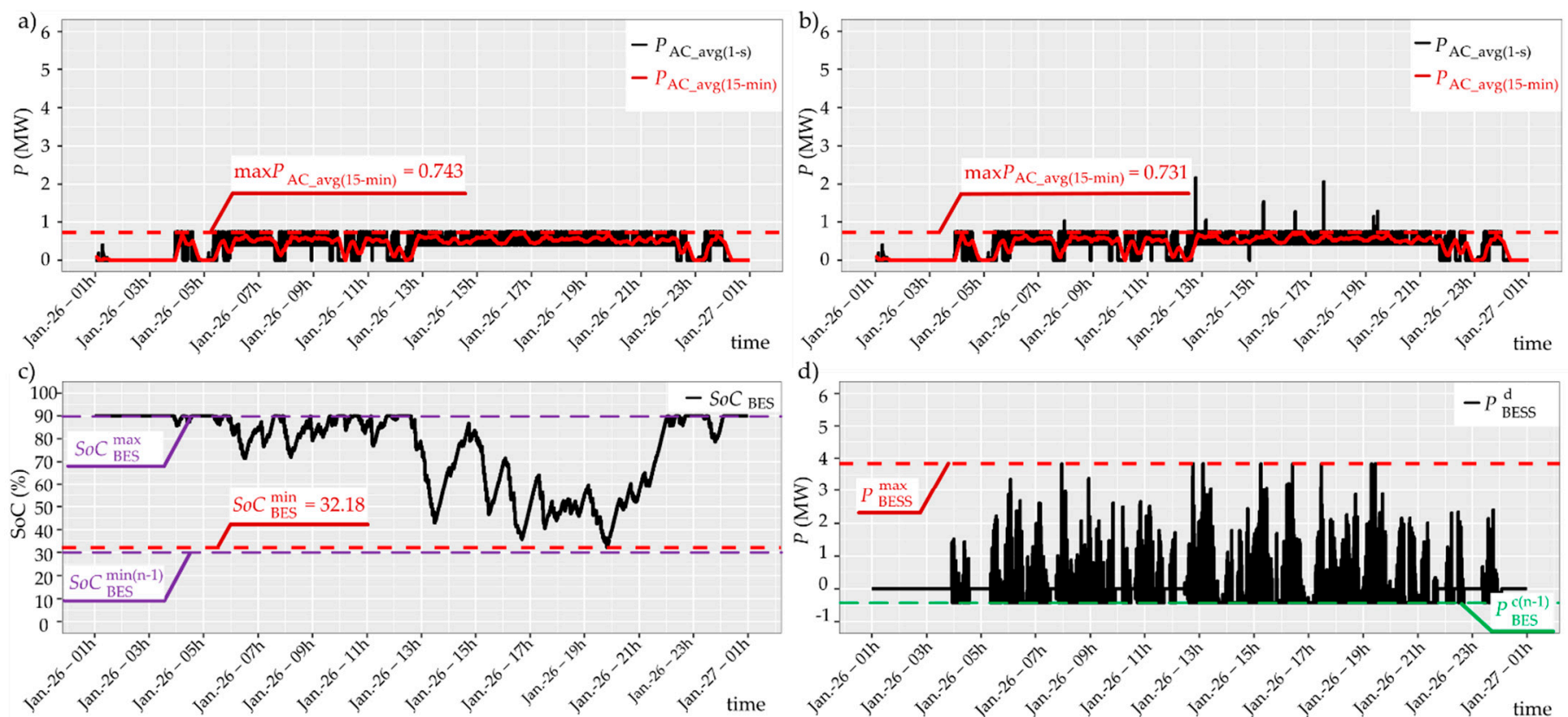

Figure 11. Simulation results in 1-day period: (a) AC side power $P_{\mathrm{AC}}$ with a fully active $\mathrm{BESS}$, (b) AC side power $P_{\mathrm{AC}}$ in CASE I $\mathrm{I}_{\mathrm{A}}(\mathrm{n}-1),(\mathbf{c})$ estimated state of charge $S o C_{\mathrm{BES}}$ of BES, (d) estimated BESS power $P_{\mathrm{BESS}}^{\mathrm{d}}$.

Figure 12 shows the simulation results of three-string BESS in CASE $I_{B}$ for (n-1) state, where: $P_{\mathrm{BESS}}^{\max }=3.840 \mathrm{MW}$, and $S o C_{\mathrm{BES}}^{\min (\mathrm{n}-2)}=20 \%, E_{\mathrm{BES}}^{\max }=0.916 \mathrm{MWh}, P_{\mathrm{BES}}^{\mathrm{c}(\mathrm{n}-2)}=0.380 \mathrm{MW}$, $P_{\text {Dem }}=0.750 \mathrm{MW}$. 

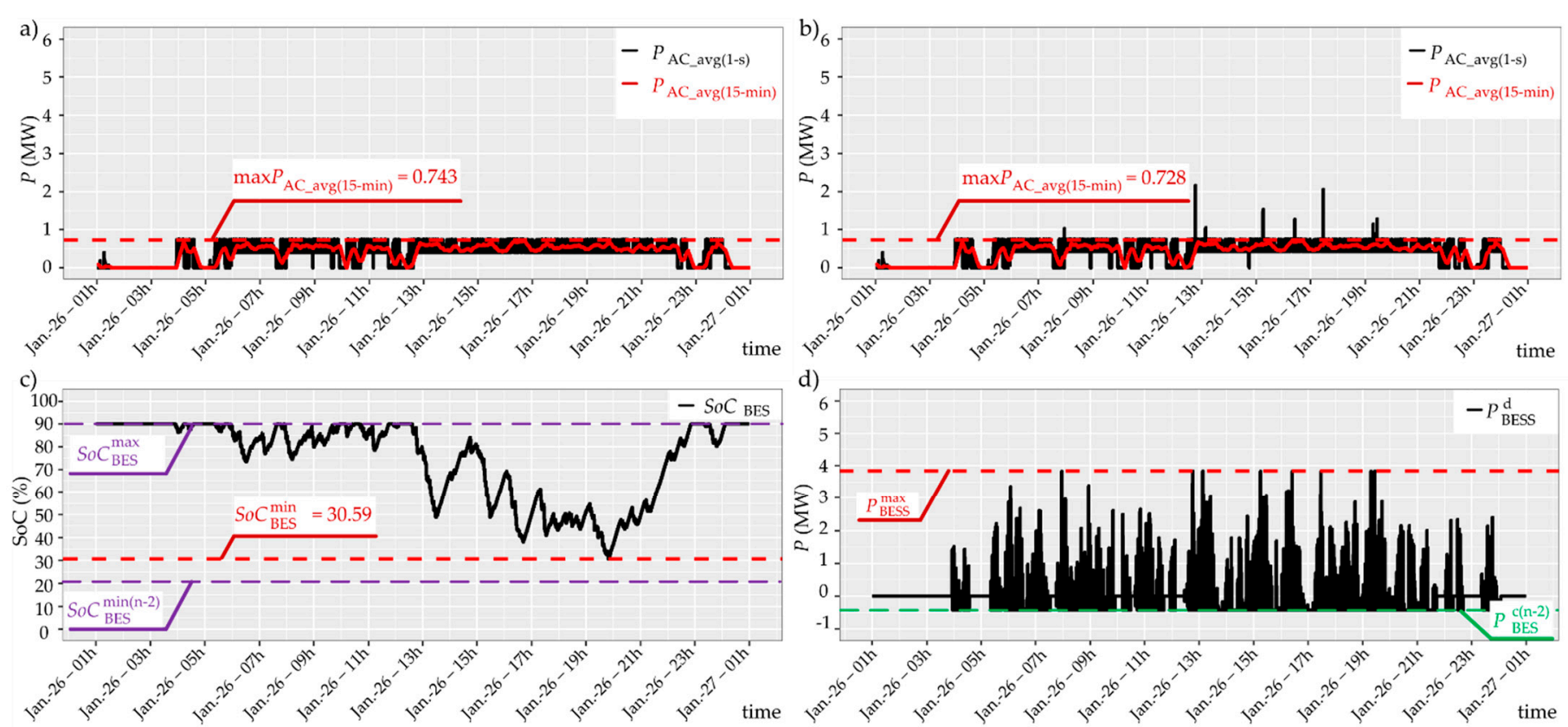

Figure 12. Simulation results in 1-day period: (a) AC side power $P_{\mathrm{AC}}$ with a fully active BESS, (b) AC side power $P_{\mathrm{AC}}$ in CASE $_{\mathrm{B}}(\mathrm{n}-1)$, (c) estimated state of charge $S o C_{\mathrm{BES}}$ of BES, (d) estimated BESS power $P_{\mathrm{BESS}}^{\mathrm{d}}$.

Figure 13 shows the simulation results of three-string BESS in CASE $\mathrm{I}_{\mathrm{C}}$ for $(\mathrm{n}-2)$ state, where: $P_{\mathrm{BESS}}^{\max }=1.920 \mathrm{MW}$, and $S o C_{\mathrm{BES}}^{\min (\mathrm{n}-2)}=20 \%, E_{\mathrm{BES}}^{\max }=0.458 \mathrm{MWh}, P_{\mathrm{BES}}^{\mathrm{c}(\mathrm{n}-2)}=0.380 \mathrm{MW}$, $P_{\text {Dem }}=0.750 \mathrm{MW}$.
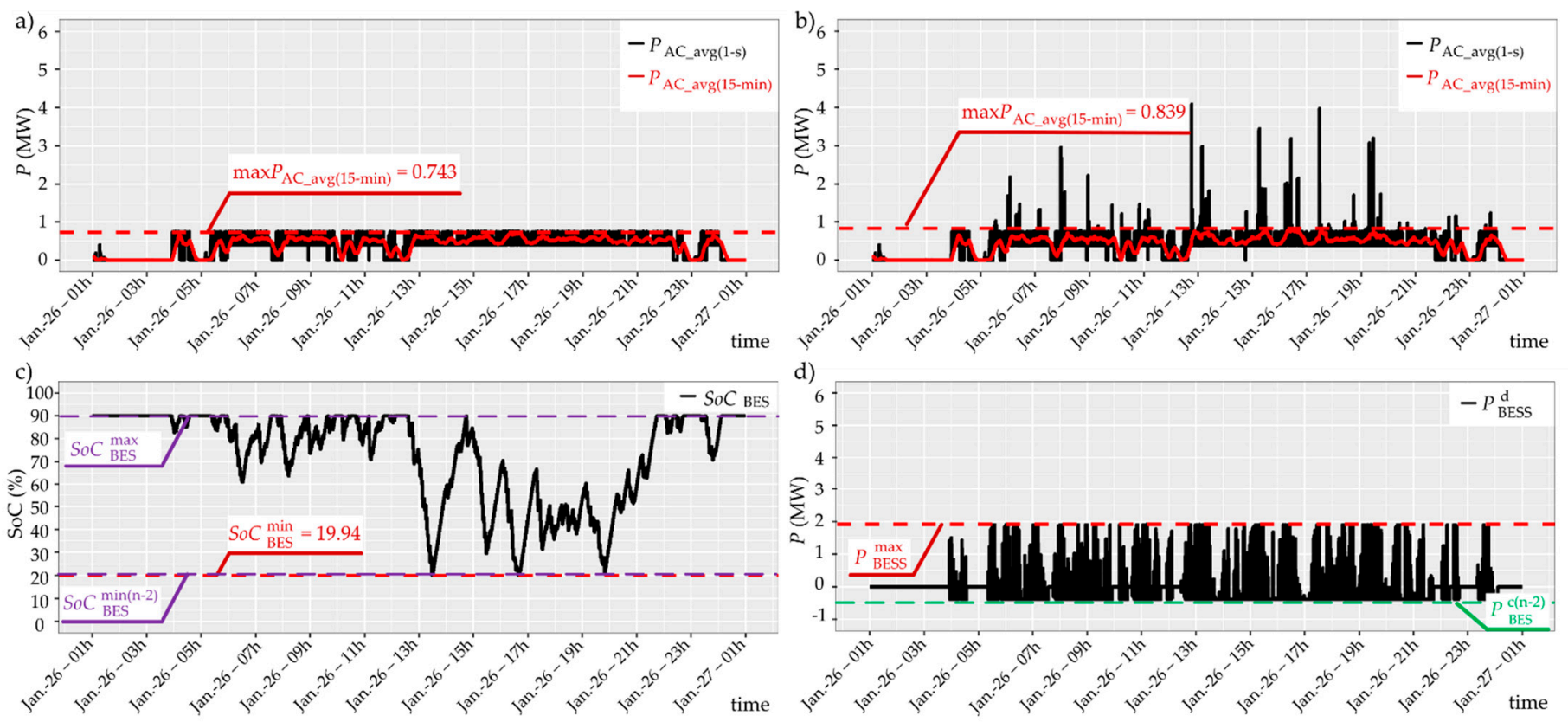

Figure 13. Simulation results in 1-day period: (a) AC side power $P_{\mathrm{AC}}$ with a fully active BESS, (b) AC side power $P_{\mathrm{AC}}$ in CASE $I_{C}(n-2),(c)$ estimated state of charge $S o C_{B E S}$ of BES, (d) estimated BESS power $P_{\mathrm{BESS}}^{\mathrm{d}}$.

Figure 14 shows the simulation results of three-string BESS in CASE $\mathrm{II}_{\mathrm{A}}$ for $(\mathrm{n}-1)$ state, where: $P_{\mathrm{BESS}}^{\max }=3.360 \mathrm{MW}$, and $S o C_{\mathrm{BES}}^{\min (\mathrm{n}-1)}=30 \%, E_{\mathrm{BES}}^{\max }=0.687 \mathrm{MWh}, P_{\mathrm{BES}}^{\mathrm{c}(\mathrm{n}-1)}=0.400 \mathrm{MW}$, $P_{\text {Dem }}=0.750 \mathrm{MW}$. 

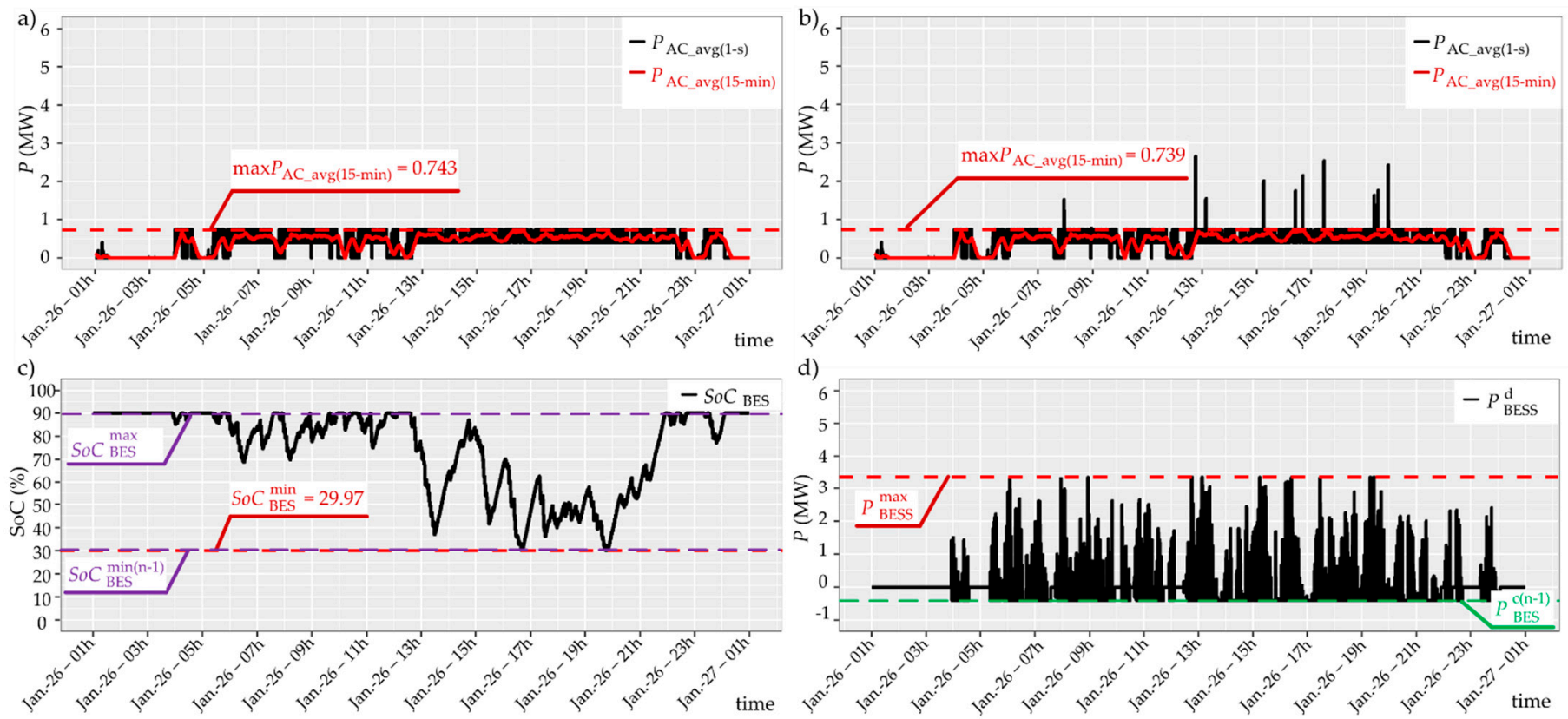

Figure 14. Simulation results in 1-day period: (a) AC side power $P_{\mathrm{AC}}$ with a fully active BESS, (b) AC side power $P_{\mathrm{AC}}$ in CASE II $(n-1)$, (c) estimated state of charge $S o C_{\mathrm{BES}}$ of BES, (d) estimated BESS power $P_{\mathrm{BESS}}^{\mathrm{d}}$.

Figure 15 shows the simulation results of a three-string BESS in CASE $\mathrm{II}_{\mathrm{B}}$ for $(\mathrm{n}-1)$ state, where: $P_{\mathrm{BESS}}^{\max }=3.360 \mathrm{MW}$, and $S o C_{\mathrm{BES}}^{\min (\mathrm{n}-2)}=20 \%, E_{\mathrm{BES}}^{\max }=0.802 \mathrm{MWh}, P_{\mathrm{BES}}^{\mathrm{c}(\mathrm{n}-2)}=0.380 \mathrm{MW}$, $P_{\text {Dem }}=0.750 \mathrm{MW}$.
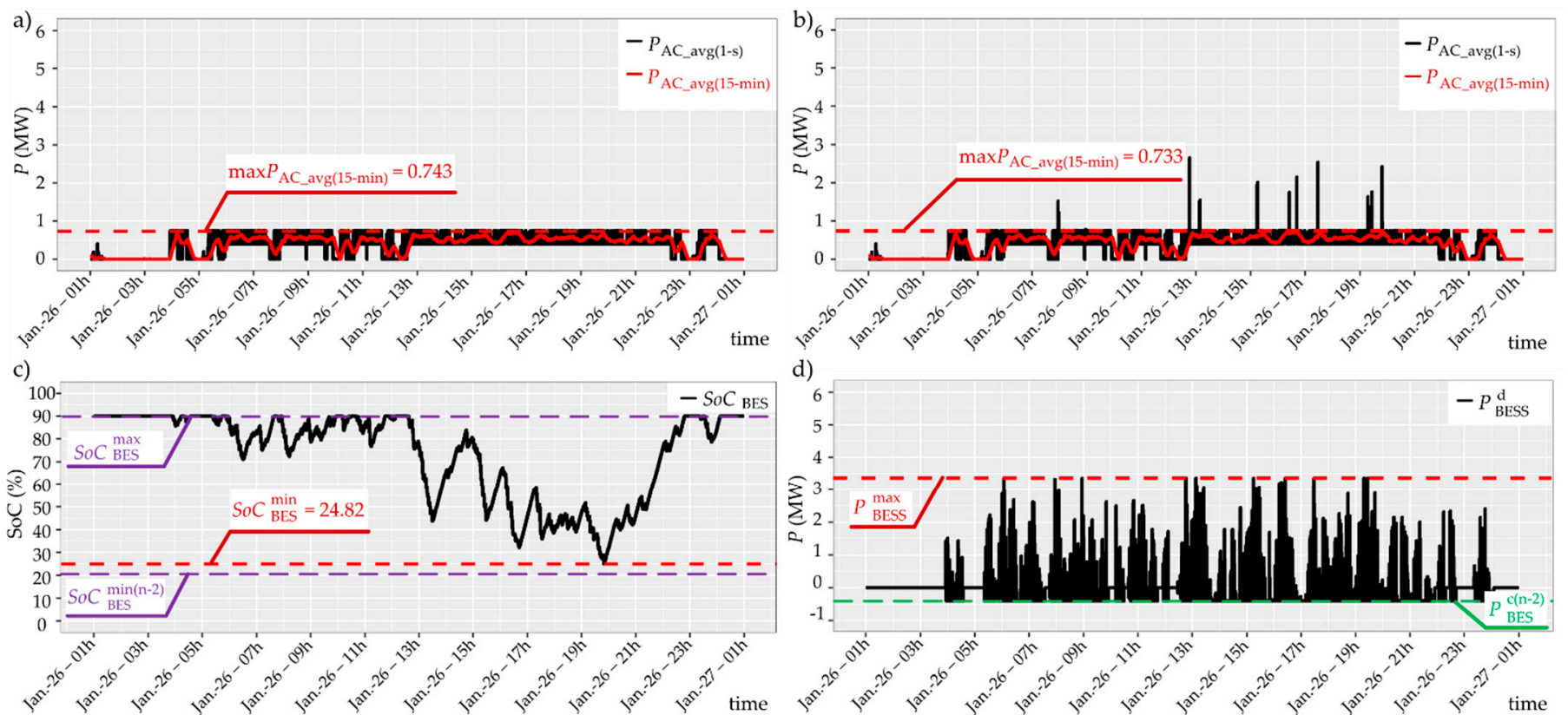

Figure 15. Simulation results in 1-day period: (a) AC side power $P_{\mathrm{AC}}$ with a fully active BESS, (b) AC side power $P_{\mathrm{AC}}$ in CASE $I_{B}(n-1)$, (c) estimated state of charge $S o C_{B E S}$ of BES, (d) estimated BESS power $P_{\mathrm{BESS}}^{\mathrm{d}}$.

Figure 16 shows the simulation results of a four-string BESS in CASE III $\mathrm{A}_{\mathrm{A}}$ for $(\mathrm{n}-1)$ state, where: $P_{\mathrm{BESS}}^{\max }=3.960 \mathrm{MW}$, and $S o C_{\mathrm{BES}}^{\min (\mathrm{n}-1)}=30 \%, E_{\mathrm{BES}}^{\max }=0.810 \mathrm{MWh}, P_{\mathrm{BES}}^{\mathrm{c}(\mathrm{n}-1)}=0.400 \mathrm{MW}$, $P_{\text {Dem }}=0.750 \mathrm{MW}$. 

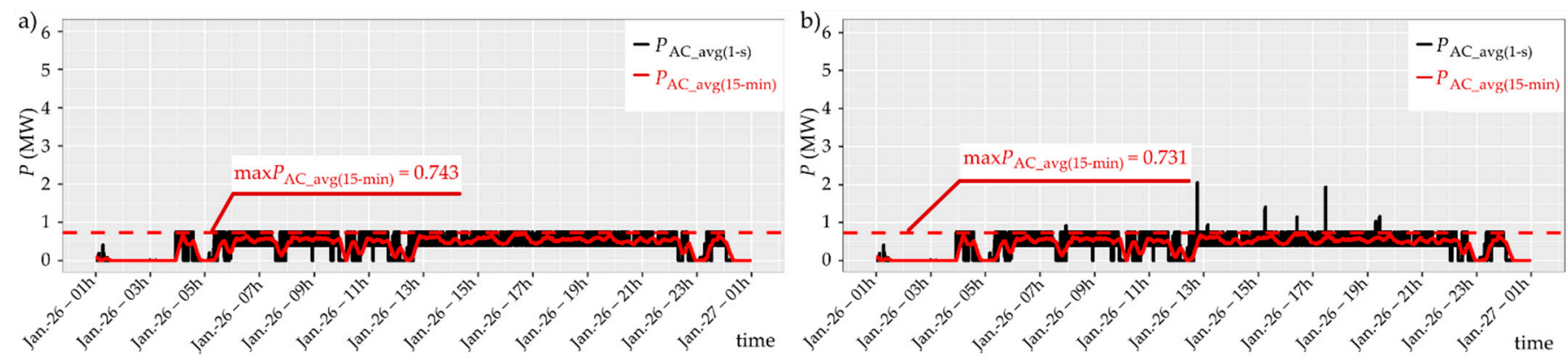

c)
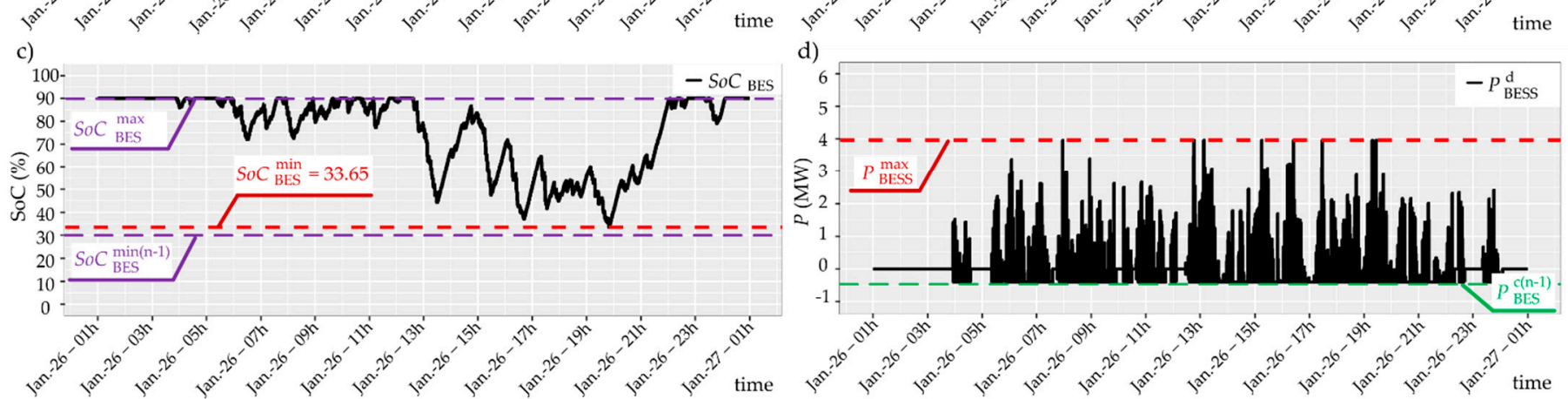

Figure 16. Simulation results in 1-day period: (a) AC side power $P_{\text {AC }}$ with a fully active BESS, (b) AC side power $P_{\text {AC }}$ in CASE $\mathrm{III}_{\mathrm{A}}(\mathrm{n}-1),(\mathbf{c})$ estimated state of charge $S o C_{\mathrm{BES}}$ of BES, (d) estimated BESS power $P_{\mathrm{BESS}}^{\mathrm{d}}$.

Figure 17 shows the simulation results of a four-string BESS in CASE $\mathrm{III}_{\mathrm{B}}$ for $(\mathrm{n}-1)$ state, where: $P_{\mathrm{BESS}}^{\max }=3.960 \mathrm{MW}$, and $S o C_{\mathrm{BES}}^{\min (\mathrm{n}-2)}=20 \%, E_{\mathrm{BES}}^{\max }=0.945 \mathrm{MWh}, P_{\mathrm{BES}}^{\mathrm{c}(\mathrm{n}-2)}=0.380 \mathrm{MW}$, $P_{\text {Dem }}^{\lim }=0.750 \mathrm{MW}$.
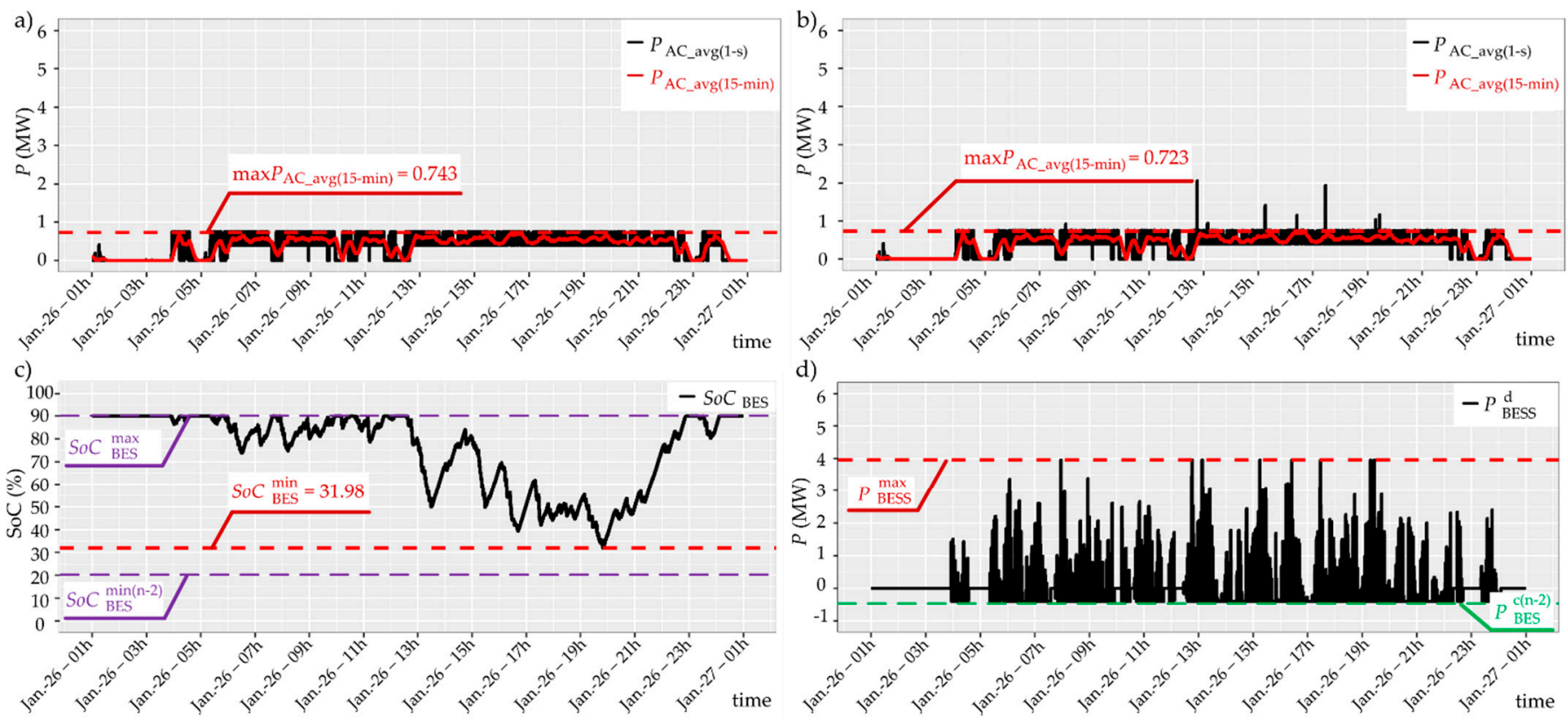

Figure 17. Simulation results in 1-day period: (a) AC side power $P_{\mathrm{AC}}$ with a fully active BESS, (b) AC side power $P_{\mathrm{AC}}$ in CASE $\mathrm{III}_{\mathrm{B}}(\mathrm{n}-1),(\mathbf{c})$ estimated state of charge $S o C_{\mathrm{BES}}$ of BES, (d) estimated BESS power $P_{\mathrm{BESS}}^{\mathrm{d}}$.

Figure 18 shows the simulation results of four-string BESS in CASE $\mathrm{III}_{\mathrm{C}}$ for (n2) configuration, where: $P_{\mathrm{BESS}}^{\max }=2.630 \mathrm{MW}$, and $S o C_{\mathrm{BES}}^{\min (\mathrm{n}-2)}=20 \%, E_{\mathrm{BES}}^{\max }=0.630 \mathrm{MWh}$, $P_{\mathrm{BES}}^{\mathrm{c}(\mathrm{n}-2)}=0.380 \mathrm{MW}, P_{\text {Dem }}^{\lim }=0.750 \mathrm{MW}$. 

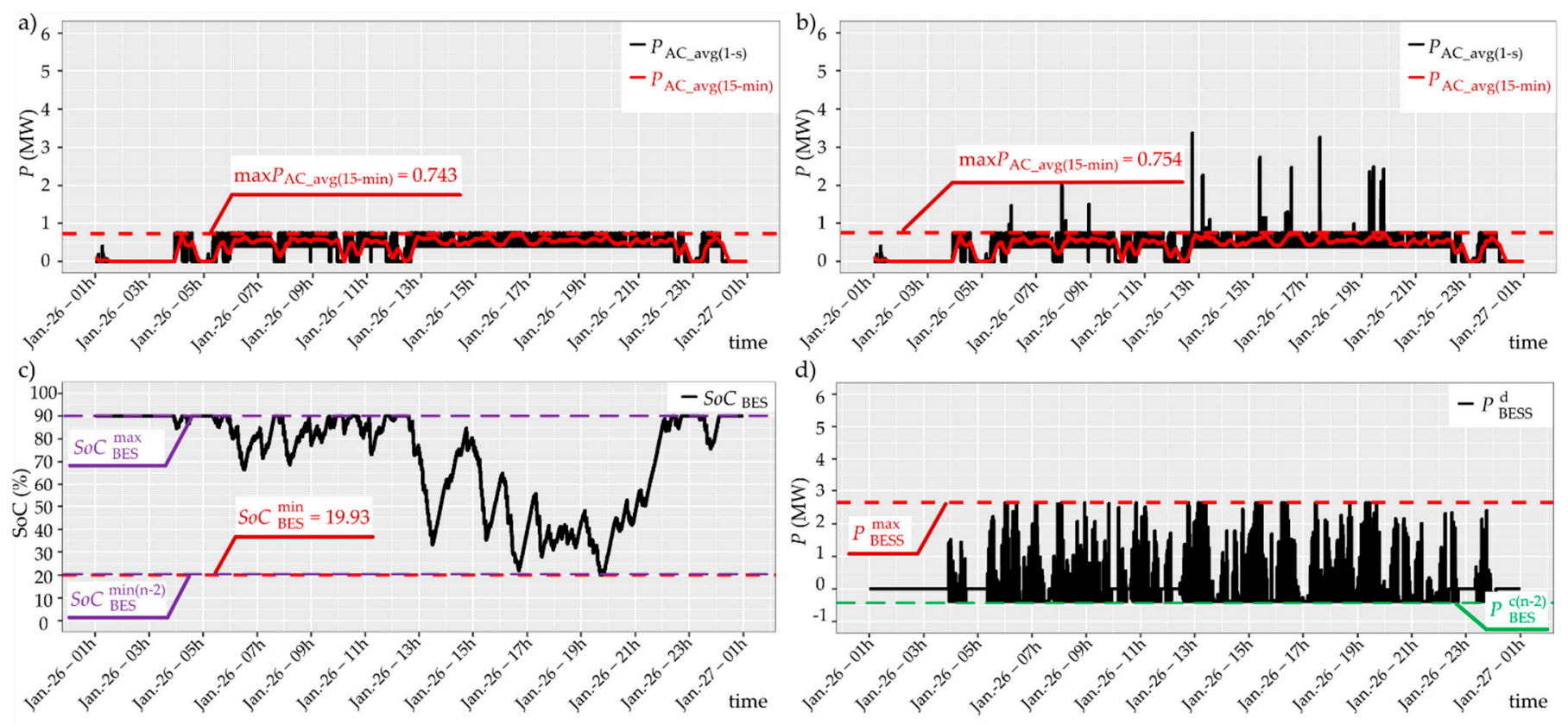

Figure 18. Simulation results in 1-day period: (a) AC side power $P_{\mathrm{AC}}$ with a fully active BESS, (b) AC side power $P_{\mathrm{AC}}$ in CASE III $(\mathrm{n}-2)$, (c) estimated state of charge $S o C_{\text {BES }}$ of BES, (d) estimated BESS power $P_{\text {BESS. }}^{\text {d }}$.

\section{Discussion of the Simulation Results}

Section 5 presents the simulation research results of multi-string BESS (Figures 9 and 10) being the major part of DROPT-FTC system, controlled by the control algorithm shown in Figure 8 and responsible for BESS control in failure-free (n) and in emergency (n-1 and $\mathrm{n}-2$ ) states. Taking into account the parameters of the real DROPT system with a rated power 5.5 MW and rated energy 1.8 MWh, a three-string BESS structure (Figure 9) with an asymmetrical distribution of power (two PCS with a rated power of $2.0 \mathrm{MW}$ and one $1.5 \mathrm{MW}$ ) and a four-string BESS structure (Figure 10) with an symmetrical distribution of power (four PCS with a rated power equal to $1.375 \mathrm{MW}$ ) were proposed and researched. The real available power was limited to $96 \%$, according to PCS systems efficiency, while the available energy of BES in relation to the rated energy was limited by the $S o C_{\mathrm{BES}}^{\max }$ and $S_{0} C_{\mathrm{BES}}^{\min (\mathrm{n})}$ thresholds.

Figure $11\left(\mathrm{CASE} \mathrm{I}_{\mathrm{A}}\right)$ and Figure $14\left(\mathrm{CASE} \mathrm{II}_{\mathrm{A}}\right)$ show the simulation research results carried out with the control with a two-threshold reduction strategy and a one-level BESS available power reduction $P_{\mathrm{BESS}}^{\mathrm{n}-1}$ of three-string BESS, while the Figure $16\left(\mathrm{CASE} \mathrm{III}_{\mathrm{A}}\right)$ of four-string BESS. For these cases, the reduced available energy $E_{\mathrm{BES}}^{\max }$ was compensated by lowering the minimum discharge level to $S o C_{\mathrm{BES}}^{\min (\mathrm{n}-1)}$.

Figure $13\left(\mathrm{CASE} \mathrm{I}_{\mathrm{C}}\right.$ ) shows the simulation research results carried out with the control with a three-threshold reduction strategy and a two-level BESS available power reduction $P_{\mathrm{BESS}}^{\mathrm{n}-2}$ of a three-string BESS, while in Figure 18 (CASE III $\mathrm{C}$ ) of a four-string BESS. For these cases, the reduced available energy $E_{\mathrm{BES}}^{\max }$ was compensated by lowering the minimum discharge level to $S o C_{\mathrm{BES}}^{\min (\mathrm{n}-2)}$.

Additionally, in a system with a two-threshold reduction strategy and a one-level BESS available power reduction $P_{\mathrm{BESS}}^{\mathrm{n}-1}$ an analysis was performed with a two-stage discharge level reduction $\left(S o C_{\mathrm{BES}}^{\min (n-2)}\right)$, which in fact means increasing the available energy $E_{\mathrm{BES}}^{\max }$. Figure $12\left(\mathrm{CASE} \mathrm{I}_{\mathrm{B}}\right)$, Figure $15\left(\mathrm{CASE} \mathrm{II}_{\mathrm{B}}\right)$ and Figure $17\left(\mathrm{CASE} \mathrm{III}_{\mathrm{B}}\right)$ show the simulation research results in such cases.

The results of simulation research have been summarized in Table 5 . 
Table 5. Comparison of the demanded $15 \mathrm{~min}$ power level of selected cases of proposed DROPT-FTC structures in three operating status.

\begin{tabular}{|c|c|c|c|c|c|c|c|c|c|}
\hline \multirow{2}{*}{ Parameters } & \multirow{2}{*}{$\begin{array}{c}\text { Base } \\
\begin{array}{c}\text { Normal } \\
\text { (n) }\end{array}\end{array}$} & \multicolumn{5}{|c|}{ Three-String BESS } & \multicolumn{3}{|c|}{ Four-String BESS } \\
\hline & & $\underset{(\mathrm{n}-1)}{\operatorname{CASE} \mathrm{I}_{\mathrm{A}}}$ & $\underset{(\mathrm{n}-1)}{\operatorname{CASE} I_{B}}$ & $\underset{(\mathrm{n}-2)}{\mathrm{CASE} \mathrm{I}_{\mathrm{C}}}$ & $\underset{(\mathrm{n}-1)}{\mathrm{CASE} \mathrm{II}_{\mathrm{A}}}$ & $\underset{(\mathrm{n}-1)}{\mathrm{CASE}^{-1} \mathrm{I}_{\mathrm{B}}}$ & $\begin{array}{c}\text { CASE } \\
\text { III }_{\text {A }} \\
(\mathbf{n}-1)\end{array}$ & $\begin{array}{c}\text { CASE } \\
\text { III }_{\text {B }} \\
(\mathrm{n}-1)\end{array}$ & $\begin{array}{c}\text { CASE } \\
\text { III } \\
(\mathbf{n}-2)\end{array}$ \\
\hline$P_{\mathrm{BESS}}^{\max }(\mathrm{MW})$ & 5.260 & 3.840 & 3.840 & 1.920 & 3.360 & 3.360 & 3.960 & 3.960 & 2.630 \\
\hline$E_{\mathrm{BES}}^{\max }(\mathrm{MWh})$ & 0.900 & 0.786 & 0.916 & 0.458 & 0.687 & 0.802 & 0.810 & 0.945 & 0.630 \\
\hline$S o C_{\mathrm{BES}}^{\max }(\%)$ & 90 & 90 & 90 & 90 & 90 & 90 & 90 & 90 & 90 \\
\hline$S o C_{\mathrm{BES}}^{\min }(\%)$ & 40 & 30 & 20 & 20 & 30 & 20 & 30 & 20 & 20 \\
\hline$P_{\mathrm{BES}}^{\mathrm{c}}(\mathrm{MW})$ & 0.420 & 0.400 & 0.380 & 0.380 & 0.400 & 0.380 & 0.400 & 0.380 & 0.380 \\
\hline$P_{\text {Dem }}^{\lim }(\mathrm{MW})$ & 0.750 & 0.750 & 0.750 & 0.750 & 0.750 & 0.750 & 0.750 & 0.750 & 0.750 \\
\hline$P_{\text {Dem_AC_avg }(15-\lim )}^{\lim }(\mathrm{MW})$ & 0.743 & 0.731 & 0.728 & $\underline{0.839}$ & 0.739 & 0.732 & 0.731 & 0.723 & $\underline{0.754}$ \\
\hline
\end{tabular}

Bolded values do meet the assumption $P_{\text {Dem__AC_avg }(15-\min )}^{\lim } \leq P_{\mathrm{Dem}}^{\lim }$. Bolded and underlined value do not meet the assumption. Bolded and double underlined value can meet the assumptions.

As can be concluded from the data presented in Table 5, it is possible to maintain the reduced level of the demanded power $P_{\text {Dem_AC_avg }(15-\min )}$ on the AC side of the traction substation at the assumed level of $0.75 \mathrm{MW}$ in several considered scenarios when the DROPT-FTC system operates in emergency states.

The two-threshold reduction strategy $\left(\mathrm{CASE} \mathrm{I}_{\mathrm{A}}, \mathrm{CASE} \mathrm{II}_{\mathrm{A}}, \mathrm{CASE} \mathrm{III}_{\mathrm{A}}\right)$ fulfills the assumption quite easily, in the event of the failure state of only one segment of BESS. A more complicated situation seems to be in cases when two segments of BESS are damage or disconnected. In such cases a three-threshold reduction strategy is involved in DROPT-FTC system. The simulations showed that in a three-string BESS, with two PCS or BES damaged or disconnected, when the available power is equal to $P_{\mathrm{BESS}}^{\mathrm{n}-2}=1.92 \mathrm{MW}$ $\left(\mathrm{CASE} \mathrm{I}_{\mathrm{C}}\right.$ ) and the available energy compensated by reduction $S o C_{\mathrm{BES}}^{\min (\mathrm{n}-2)}=20 \%$ is equal to $E_{\mathrm{BES}}^{\max }=0.458 \mathrm{MWh}$, using the proposed control strategy the result does not meet the assumption because $P$ Dem_AC_avg $(15-\min )=0.839 \mathrm{MW}$ this value is higher than the assumed level of $0.75 \mathrm{MW}$. Definitely better results have been obtained in a four-string BESS, where the available power was equal to $P_{\mathrm{BESS}}^{\mathrm{n}-2}=2.630 \mathrm{MW}\left(\mathrm{CASE} \mathrm{III}_{\mathrm{C}}\right)$ and the available energy compensated by reduction $S o C_{\mathrm{BES}}^{\min (n-2)}=20 \%$ was equal to $E_{\mathrm{BES}}^{\max }=0.63 \mathrm{MWh}$. The demanded power reached the value $P_{\text {Dem_AC_avg }(15-\min )}=0.754 \mathrm{MW}$ and was only slightly higher than assumed.

According to the simulation research results, carried out for extreme case (CASE $\mathrm{III}_{\mathrm{C}}$ ) we conclude that the proposed control strategy implemented in the four-string BESS structure meets our expectations. In this case, the available power of a BESS equal to 2.63 MW in the event of failure of two BESS segments (two PCS or BES) is half of the rated power (5.26 MW in a fully operational BESS). However, implementation of the control strategy in the three-string BESS structure does not meet our assumptions, because the value of available power in the failure event of two PCS or BES segments (CASE $I_{C}$ ) is too low, and even increasing of the available energy $E_{\mathrm{BES}}^{\max }$ by reducing the minimum $\mathrm{BES}$ discharge level $S o C_{\mathrm{BES}}^{\min }$ from $40 \%$ to $20 \%$ does not bring the expected result. Thus, the limitation of the available power of a BESS to a half of rated power is the limit for the implementation of the proposed control method. In such a case it allows maintaining of the contracted, demanded power $P_{\text {Dem_AC_avg }(15-\min )}$ at the assumed level of $0.75 \mathrm{MW}$.

\section{Operational Expenditure}

In the considered TS fixed operating cost $\mathrm{OPEX}_{\mathrm{TS}}$ related to contracted capacity fee

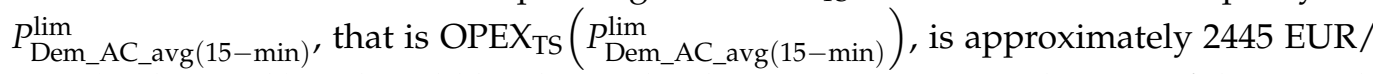
MW (each month) and could be changed only once a year. So in the case of the consid- 
ered traction substation with the rated power $P_{\text {Dem_AC_avg }(15-\min )}^{\lim }=0.75 \mathrm{MW}$, the operating cost of the TS is approximately equal $\operatorname{OPEX}_{\mathrm{TS}}\left(P_{\operatorname{Dem} \_A C \_a v g}^{\lim (15-m i n)}\right) \cong 1834 \mathrm{EUR}$ (each month).

Each breach of the contracted power limit in the time window exceeding $10 \mathrm{~min}$ (in accordance with the standard EN 50160: 2010 [37]) leads to a situation in which the TS operator is obliged to pay a contractual penalty to the local Distribution System Operator (DSO). The proposed control algorithm and multi-string structure of DROPT-FTC allows operation in emergency states with or without significant exceeding of contracted power as well as to keeping operating costs $\mathrm{OPEX}_{\mathrm{TS}}$ at constant level.

\section{Conclusions}

In this paper the concept of fault tolerant control (FTC) of a multi-string battery energy storage system (BESS) being a part of the dynamic power reduction of traction substation load (DROPT) was proposed and verified. The proposed concept is based on a multi-task control algorithm and takes into account: a three-threshold power limitation of the traction substation (TS) and two level reduction of available power of BESS. The proposed control strategy allows to realize the major task, that is, to maintain the contracted, demanded power $P_{\text {Dem_AC_avg }}(15-\min )$ of the considered TS at the required level of $0.75 \mathrm{MW}$, in the event of failure of one or two PCS or BES segments.

In order to verify the proposed control method, two BESS structure were proposed and verified, three-string and four-string. On the basic of the simulation research results, we can unequivocally state that the proposed control strategy is feasible in four-string BESS in emergency operation state even when two PCS or BES segments are in a failure state. In the three-string, asymmetrical BESS it is valid only when one PCS or BES is in a failure state.

The proposed control method and threshold values can be optimal for BESS objects with an even number of PCS segments (with the same power each) and BES (with the same energy), for example in the presented four-string structure. This method can bring more favourable results if all BES are connected to common DC bus and successively separated by connectors.

The proposed concept of FTC may be an extension control strategy to the those one previously implemented in real DROPT system (without FTC) and may be used in all DROPT systems. However each object (each traction substation with DROPT) should be considered individually for instance taking into account specific value of demanded power $P$ Dem_AC_avg(15-min), BESS rated power and energy, and need to determine the individual thresholds in the FTC method.

According to the authors of this paper, multi-string BESS and the corresponding fault tolerant control make it possible to avoid additional charges (contractual penalties) related to exceeding $P_{\text {Dem_AC_avg }}^{\text {lim }(15-\min )}$, and in extreme cases to limit exceeding the this power, which will slightly increase the $\operatorname{OPEX} X_{\mathrm{TS}}\left(P_{\mathrm{Dem} \_\mathrm{AC} \_\mathrm{avg}(15-\min )}^{\lim }\right)$, especially that the service response time to the removal of a defect is a maximum of $24 \mathrm{~h}$ and results directly from the contract between the investor and integrator of the implementation of BESS in the TS system.

\section{Future Work}

The analysis of the proposed DROPT-FTC, the proposed control algorithm and two BESS structures give us an idea of the possibility of its continuous operation in an emergency state and the behaviour of the main purpose, which is the reduction of demanded 15-min power. The presented analysis gives us information about the possibility of using a modernized control algorithm based on self-adaptation, which will be the subject and topic of the future paper. 
Author Contributions: M.S. was the principle author tasked with coordinating and writing the article; proposed a control strategy of the DROPT-FTC system and performed the simulation on real measurement data; M.J., J.K., Ł.P. performed measurement of power flow and analysed the object; M.J., J.K. proposed the DROPT system; S.W. verification of the experimental research results. The authors equally contributed to the creation of the proposed system. All authors have read and agreed to the published version of the manuscript.

Funding: This research was supported by grant from Programme Smart Growth 2014-2020 and co-funding by Polish National Center for Research and Development within the Sectoral Programme PBSE, application no POIR.01.02.00-00-0230/16 under the title "System of dynamic reduction of traction substation load, operating with the use of high power storage" (DROPT).

Institutional Review Board Statement: Not applicable.

Informed Consent Statement: Not applicable.

Data Availability Statement: Not applicable.

Acknowledgments: The research was supported by the Research and Development Office of PKP Energetyka S.A.

Conflicts of Interest: The authors declare no conflict of interest.

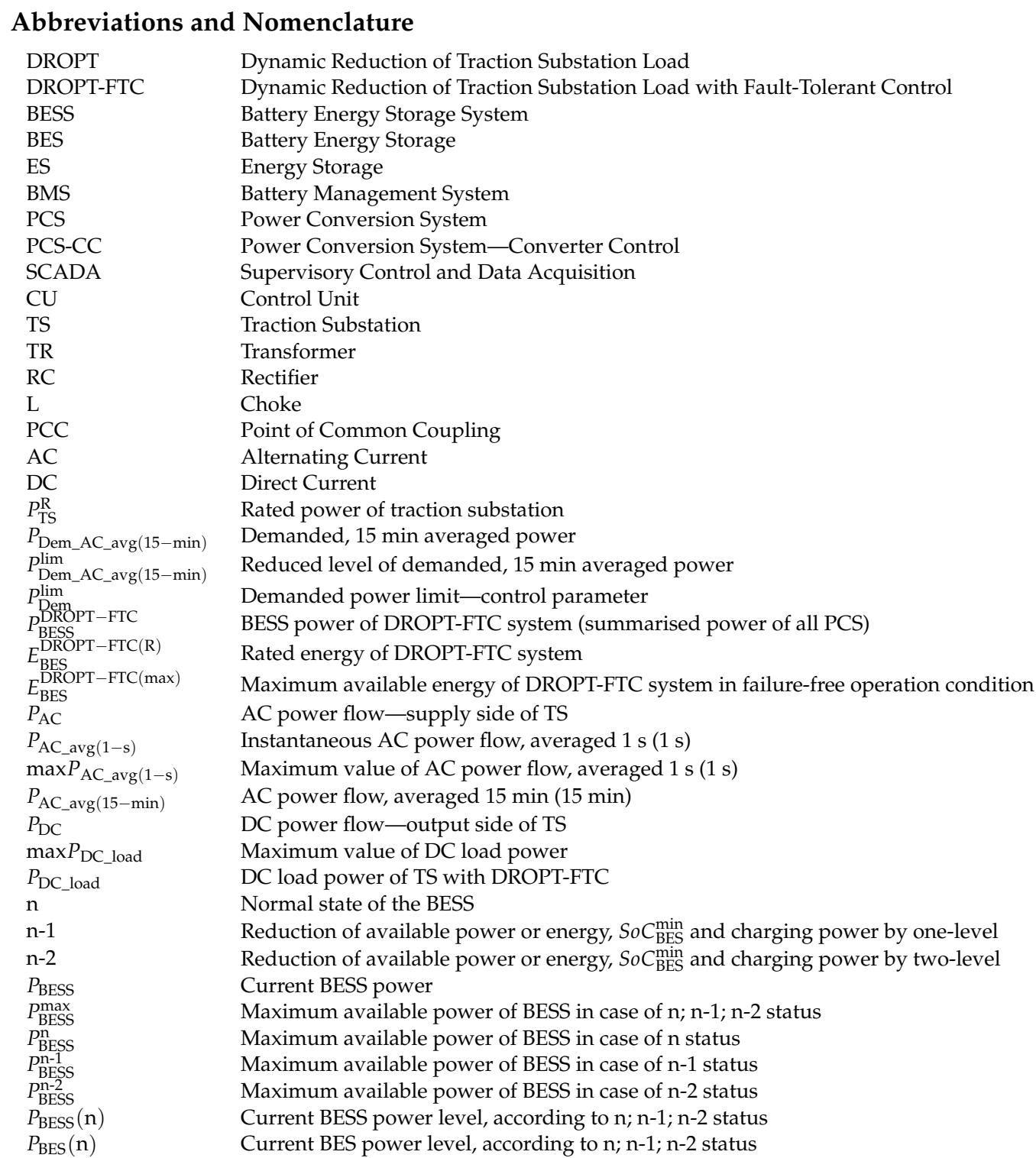




\begin{tabular}{|c|c|}
\hline$P_{\mathrm{PCS}}$ & Total power of available PCS systems, according to $n ; n-1 ; n-2$ status \\
\hline$P_{\mathrm{BESS}}^{\mathrm{d}}$ & Power taken from BESS \\
\hline$P_{\mathrm{BES}}^{\mathrm{c}}(\mathrm{n})$ & Charging power of BES, according to n; $\mathrm{n}-1 ; \mathrm{n}-2$ status \\
\hline$P_{\mathrm{BES}}^{\mathrm{c}(\mathrm{n})}$ & Maximum charging power of BES in case of $n$ status \\
\hline$P_{\mathrm{BES}}^{\mathrm{c}(\mathrm{n}-1)}$ & Maximum charging power of BES in case of $n-1$ status \\
\hline$P_{\mathrm{BES}}^{\mathrm{c}(\mathrm{n}-2)}$ & Maximum charging power of BES in case of $n-2$ status \\
\hline$E_{\mathrm{BES}}(\mathrm{n})$ & Current BES energy level, according to n; $n-1 ; n-2$ status \\
\hline$E_{\mathrm{BES}}^{\max }$ & Maximum available energy of BES in case of $n ; n-1 ; n-2$ status \\
\hline$E_{\mathrm{BES}}^{\mathrm{n}}$ & Maximum available energy of BES in case of $n$ status \\
\hline$E_{\mathrm{BES}}^{\mathrm{n}-1}$ & Maximum available energy of BES in case of $n-1$ status \\
\hline$E_{\mathrm{BES}}^{\mathrm{n}-2}$ & Maximum available energy of BES in case of $n-2$ status \\
\hline SoC $C_{\mathrm{BES}}$ & Current State of Charge of BES \\
\hline So $C_{B F S}^{\max (R)}$ & Maximum level of state of charge $(100 \%)$ \\
\hline$S o C_{\mathrm{BES}}^{\max }$ & Maximum level of state of charge (it should not exceed $90 \%$ for Li-Ion technology) \\
\hline SoC $C_{\mathrm{BES}}^{\mathrm{min}}$ & Minimum level of state of charge, according to $n ; n-1 ; n-2$ status \\
\hline$S_{0} C_{\mathrm{BES}}^{\min (\mathrm{n})}$ & Minimum level of state of charge in case of $n$ status \\
\hline$S o C_{\mathrm{BES}}^{\mathrm{min}(\mathrm{n}-1)}$ & Minimum level of state of charge in case of $n-1$ status \\
\hline$S o C_{\mathrm{BES}}^{\mathrm{min}(\mathrm{n}-2)}$ & Minimum level of state of charge in case of $n-2$ status \\
\hline$S_{0} C_{\mathrm{BES}}^{\mathrm{DES}}(\mathrm{n})$ & State of Charge of BES, according to $n ; n-1 ; n-2$ state \\
\hline$D o D_{\mathrm{BES}}$ & Depth of Discharge of BES \\
\hline C-rate & A measure of the rate at which a battery is being charge or discharge \\
\hline$O P E X_{\mathrm{TS}}$ & Operational expenditure of Traction Substation \\
\hline SPBT & Simple Payback Time \\
\hline TOU & Time-of-use \\
\hline OBESS & On-Board Energy Storage System \\
\hline WESS & Wayside Energy Storage System \\
\hline TESS & Trackside Energy Storage System \\
\hline HESS & Hybrid Energy Storage System \\
\hline HSRS & High-Speed Railway Substation \\
\hline SHB & Service Headway Breaking \\
\hline ESDI & Extending Stopping Distance Interval \\
\hline NiMH & Nickel Metal Hydride \\
\hline $\mathrm{LFP}\left(\mathrm{LiFePO}_{4}\right)$ & Lithium Iron Phosphate \\
\hline NMC & Nickle Manganese Cobalt \\
\hline
\end{tabular}

\section{References}

1. Barrero, R.; Tackoen, X.; Van Mierlo, J. Improving energy efficiency in public transport: Stationary supercapacitor based Energy Storage System for a metro network. In Proceedings of the 2008 IEEE Vehicle Power and Propulsion Conference, Harbin, China, 3-5 September 2008. [CrossRef]

2. Jefimowski, W. Stationary energy storage system in a $3 \mathrm{kV} \mathrm{DC}-$ The conception comparison. MATEC Web Conf. 2018, 180, 02013. [CrossRef]

3. Soler-Nicolau, M.; Mera, J.M.; López, J.; Cano-Moreno, J.D. Improving power supply design for high speed lines and $2 \times 25$ systems using a genetic algorithm. Electr. Power Energy Syst. 2018, 99, 309-322. [CrossRef]

4. Kim, H.; Heo, J.-H.; Park, J.-Y.; Yoon, Y.T. Impact of Battery Energy Storage System Operation Strategy on Power System: An Urban Railway Load Case under a Time-of-Use Tariff. Energies 2017, 10, 68. [CrossRef]

5. Sumpavakup, C.; Ratniyomchai, T.; Kulworawanichpong, T. Optimal energy saving in DC railway system with on-board energy storage by using peak demand cutting strategy. J. Mod. Transp. 2017, 25, 223-235. [CrossRef]

6. Kulworawanichpong, T. Multi-train modelling and simulation integrated with traction power supply solver using simplified Newton-Raphson method. J. Mod. Transp. 2015, 23, 241-251. [CrossRef]

7. Gu, Q.; Tang, T.; Cao, F.; Karimi, G.-R.; Song, Y. Peak Power Demand and Energy Consumption Reduction Strategies for Trains under Moving Block Signalling System. Hindawi Publ. Corp. Math. Probl. Eng. 2013, 2013, 940936. [CrossRef]

8. Su, S.; Tang, T.; Wang, Y. Evaluation of Strategies to Reducing Traction Energy Consumption of Metro Systems Using an Optimal Train Control Simulation Model. Energies 2016, 9, 105. [CrossRef]

9. Lin, F.; Liu, S.; Yang, Z.; Zhao, Y.; Yang, Z.; Sun, H. Multi-Train Energy Saving for Maximum Usage of Regenerative Energy by Dwell Time Optimization in Urban Rail Transit Using Genetic Algorithm. Energies 2016, 9, 208. [CrossRef]

10. Radu, P.-V.; Lewandowski, M.; Szelag, A. On-Board and Wayside Energy Storage Devices Applications in Urban Transport Systems-Case Study Analysis for Power Applications. Energies 2020, 13, 2013. [CrossRef]

11. Sumpavakup, C.; Suwannakijborihan, S.; Ratniyomchai, T.; Kulworawanichpong, T. Peak Demand Cutting Strategy with an On-Board Energy Storage System in Mass Rapid Transit. Iran. J. Sci. Technol. Trans. Electr. Eng. 2018, 42, 49-62. [CrossRef]

12. Hedlund, M.; Lundin, J.; de Santiego, J.; Abrahmsson, J.; Bernholff, H. Flywheel Energy Storage for Automotive Applications. Energies 2015, 8, 10636-10663. [CrossRef] 
13. Lin, F.; Xuyang, L.; Zhao, Y.; Yang, Z. Control Strategies with Dynamic Threshold Adjustment for Supercapacitor Energy Storage System Considering the Train and Substation Characteristics in Urban Rail Transit. Energies 2016, 9, 257. [CrossRef]

14. Khodeparastan, M.; Dutta, O.; Mohamed, A. Wayside Energy Storage System for Peak Demand Reduction in Electric Rail Systems. In Proceedings of the 2018 IEEE Industry Applications Society Annual Meeting (IAS), Portland, OR, USA, 23-27 September 2018. [CrossRef]

15. Lamedica, R.; Ruvio, A.; Palagi, L.; Mortelliti, N. Optimal Siting and Sizing of Wayside Energy Storage Systems in a D.C. Railway line. Energies 2020, 13, 6271. [CrossRef]

16. Roch-Dupré, D.; López- López, Á.-J.; Pecharromán, R.-R.; Cucala, A.-P.; Fernández-Cardador, A. Analysis of the demand charge in DC railway systems and reduction of its economic impact with Energy Storage System. Elsevier Electr. Power Energy Syst. 2017, 93, 459-467. [CrossRef]

17. Jarnut, M.; Kaniewski, J.; Protsiuk, V. Energy storage system for peak-power reduction of traction substation. In Proceedings of the 2018 Innovative Materials and Technologies in Electrical Engineering (i-MITEL), Sulecin, Poland, 18-20 April 2018. [CrossRef]

18. Calderaro, V.; Galdi, V.; Graber, G.; Picollo, A.; Capasso, A.; Lamedica, R.; Ruvio, A. Energy Management of Auxliary Battery Substation Supporting High-Speed Train on 3 kV DC Systems. In Proceedings of the 2015 International Conference on Renewable Energy Research and Applications (ICRERA), Palermo, Italy, 22-25 November 2015. [CrossRef]

19. Kwon, K.; Choi, J. Single-Phase 13-Level Power Conditioning System for Peak Power Reduction of a High-Speed Railway Substation. Energies 2019, 12, 4405. [CrossRef]

20. Jefimowski, W.; Nikitenko, A. Case study of stationary energy storage device in a $3 \mathrm{kV}$ DC traction system. MATEC Web Conf. 2018, 180, 02005. [CrossRef]

21. Qin, Q.; Guo, T.; Lin, F.; Yang, Z. Energy Transfer Strategy for Urban Rail Transit Battery Energy Storage System to reduce Peak Power of Traction Substation. IEEE Trans. Veh. Technol. 2019, 68, 11714-11724. [CrossRef]

22. Guo, T.; Yang, Z.; Lin, F.; Xiong, S. Optimization of peak load shifting control strategy for battery energy storage system used in urban rail transit. In Proceedings of the IECON 2017-43rd Annual Conference of the IEEE Industrial Electronics, Beijing, China, 29 October-1 November 2017. [CrossRef]

23. Xia, H.; Chen, H.; Yang, Z.; Lin, F.; Wang, B. Optimal Energy Management, Location and Size for Stationary Energy Storage System in a Metro Line Based on Genetic Algorithm. Energies 2015, 8, 11618-11640. [CrossRef]

24. Szott, M.; Wermiński, S.; Jarnut, M.; Kaniewski, J. Battery peak-power reduction system of traction substation with two-threshold limitation. Przeglad Elektrotechniczny 2020. [CrossRef]

25. Szott, M.; Wermiński, S.; Jarnut, M.; Kaniewski, J.; Benysek, G. Battery Energy Storage System for Emergency Supply and Improved Reliability of Power Networks. Energies 2021, 14, 720. [CrossRef]

26. Miao, Y.; Hynan, P.; von Jouanne, A.; Yokochi, A. Current Li-Ion Battery Technologies in Electric Vehicles and Opportunities for Advancement. Energies 2019, 12, 1074. [CrossRef]

27. Koniak, M.; Czerepicki, A. Selection of battery pack parameters for an electric vehicle based on performance requirements In Proceedings of the IOP Conference Series: Material Science and Engineering, Bangkok, Thailand, 21-23 April 2017. [CrossRef]

28. EN 50470-3: 2009. Electricity Metering Equipment (a.c.) Part 3: Particular Requirements-Static Meters for Active Energy (Class Index A, $B$ and C); ISS: Beograd, Serbia, 2009.

29. EN 62055-31. Electricity Metering_Payment Systems_Part 31: Particular Requirements—Static Payment Meters for Active Energy (Classes 1 and 2); IEC: Geneva, Switzerland, 2005.

30. Wei, Z.; Zhao, J.; Ji, D.; Tseng, K.J. A multi-timescale estimator for battery state of charge and capacity dual estimation based on an online identified model. Appl. Energy 2017, 204, 1264-1274. [CrossRef]

31. Chen, L.; Tong, Y.; Dong, Z. Li-Ion Battery Performance Degradation Modelling for the Optimal Design and Energy Management of Electrified Propulsion Systems. Energies 2020, 13, 1629. [CrossRef]

32. Wikner, E.; Thiringer, T. Extending Battery Lifetime by Avoiding High SOC. Appl. Sci. 2018, 8, 1825. [CrossRef]

33. Cheng, Y.-I.; Liu, Y.-H.; Hesse, H.C.; Naumann, M.; Trung, C.N.; Josson, A. A PSO-Optimized Fuzzy Logic Control-Based Charging Method for Individual Household Battery Storage System within a Community. Energies 2018, 11, 469. [CrossRef]

34. Huang, M.-C.; Yang, C.-H.; Chiang, C.-C.; Chiu, S.-C.; Chen, Y.-F.; Lin, C.-Y.; Wang, L.-Y.; Li, Y.-L.; Yang, C.-C.; Chang, W.-S. Influence of High Loading on the Performance of Natural graphite-Based Al Secondary Batteries. Energies 2018, 11, 2760. [CrossRef]

35. Haidl, P.; Buchroithner, A.; Schweighofer, B.; Bader, M.; Wegleiter, H. Lifetime Analysis of Energy Storage Systems Sustainable Transportation. Sustainability 2019, 11, 6731. [CrossRef]

36. Kurzweil, P.; Shamonin, M. State-of-Charge Monitoring by Impedance Spectroscopy during Long-Term self-Discharge of Supercapacitors and Lithium-Ion Batteries. Batteries 2018, 4, 35. [CrossRef]

37. EN 50160. Voltage Characteristics of Electricity Supplied by Public Electricity Networks; German Institute for Standardisation: Berlin, Germany, 2010. 